\title{
A fauna de peixes nas bacias do sudeste do Espírito Santo, Brasil
}

\author{
Luisa Maria Sarmento-Soares", Ronaldo Fernando Martins-Pinheiro \& Mikael Mansur Martinelli
}

Museu de Biologia Prof. Mello Leitão/Projeto BIOdiversES (www.nossosriachos.net), Av. José Ruschi, 4, Centro, Santa Teresa, Espírito Santo, Brasil.

\begin{abstract}
Resumo - As bacias hidrográficas do sudeste capixaba compreendem os sistemas hídricos dos rios Novo e Benevente e das microbacias de Guarapari. O presente estudo faz parte de uma série de trabalhos sobre a ictiofauna dos sistemas hídricos no Espírito Santo. Foram averiguados 45 pontos georreferenciados em rios e córregos da região, sendo 13 na bacia do Rio Novo, 23 no rio Benevente e nove nas microbacias, nos municípios de Anchieta, Guarapari e Vila Velha. O ambiente e a composição de peixes foram documentados em cada ponto, registrando um total de 110 espécies (54 marinhas), pertencentes a 46 famílias e 17 ordens, a maioria dos quais são Perciformes (42 espécies). Dentre as espécies de água doce, predominaram peixes das ordens Characiformes e Siluriformes, com 16 espécies cada. A Mata Atlântica na região dos rios do sudeste capixaba é composta por floresta ombrófila, floresta estacional semidecidual e formações pioneiras (brejos, restingas, mangues). Os alagados e ambientes lagunares na região das baixadas litorâneas estão submetidos a intensos distúrbios, e neste sentido, as unidades de conservação são de extrema importância para sua preservação. O endemismo regional para peixes de água doce é comentado, bem como a presença de potenciais espécies novas na área de estudo.
\end{abstract}

Palavras-chave adicionais: bacia hidrográfica, biodiversidade, endemismo, ictiofauna, peixe de riacho.

\begin{abstract}
Fish fauna from the basins of southeastern Espírito Santo, Brazil) - The hydrographic basin of southeastern Espírito Santo comprises the systems of Rio Novo, Rio Benevente and small river basins of the Guarapari. The present study is part of a series of studies on the fish fauna of river basins in Espírito Santo State. Fourty-five geo-referrerenced points in rivers and rivulets of the region were evaluated, 13 in the Rio Novo basin, 23 in the Rio Benevente basin and nine in small river basins in the municipalities of Anchieta, Guarapari, and Vila Velha. The environment and fish fauna were documented at every point, reporting a total of 110 species (54 marine), belonging to 46 families and 17 orders, most of which are Perciformes (42 species). With the exception of marine species, most of the fishes belong to the orders Characiformes and Siluriformes, with 16 species each. The Atlantic forest along the rivers of southeastern Espírito Santo region is composed of ombrophylous forest, pluvial submontane forest and pioneer formations (swamps, coastal sand dunes, and mangroves). The wetlands and coastal lake environments in the area are submitted to intense disturbances, and in this sense, the conservation units are extremely important for their preservation. The regional endemism of freshwater fishes is commented on, as well as the presence of potentially new species in the study area.
\end{abstract}

Additional key words: biodiversity, endemism, freshwater river fish, hydrographic basin, ichthyofauna.

Em certa quadra do ano apanha-se uma infinita quantidade de peixes; a isso os Indios chamam pirá-iquê, isto é, "entrada dos peixes"; porquanto vem inumeros deles de diversas partes do mar, entram para os lugares estreitos e de pouco fundo do mar, afim de pôrem as ovas.

Pe José de Anchieta (1560)

Os peixes de riacho no Espírito Santo abrangem um conjunto peculiar, com diversas espécies de pequeno porte, associadas a uma gama de ambientes, muitos destes ainda pouco explorados. Não raro, os ambientes de água doce encontram-se impactados, comprometendo a sobrevivência da ictiofauna nativa. As explorações conduzidas para a coleta de peixes no estado, em sua maioria, têm se voltado para a bacia do Rio Doce, ou englobam registros de espécies de águas estuarinas (Ruschi 1965; Paiva 2004). Ao final do século XX, estudos sobre peixes de água doce no Espírito Santo foram encomendados para organizar planos de

"Autora para correspondência: biodiverses@nossosriachos.net

Editor responsável: Alexandre Clistenes de Alcântara Santos

Submetido em: 27 set. 2010; publicação eletrônica: 11 jun. 2012 manejo de unidades de conservação e para preparar relatórios de impacto ambiental de empreendimentos no estado. Contudo, nos estudos a que tivemos acesso, não há referência a tombamento do material capturado, sendo inviável a confirmação da identidade das espécies de peixes indicadas. Nos dias de hoje, a floresta Atlântica no Espírito Santo conta com menos de 7\% da sua área original ainda inalterada. A fragmentação da Mata Atlântica e a destruição de ambientes de água doce têm sido mais rápidas do que a exploração e o conhecimento da fauna associada de peixes de riacho. Neste aspecto, a ictiofauna capixaba representa um dos componentes menos conhecidos na Mata Atlântica do sudeste do Brasil (Sarmento-Soares \& Martins-Pinheiro 2009).

Com o projeto BIOdiversES - "Distribuição e

Sitientibus série Ciências Biológicas 12(1): 1-25. 2012. 
endemismo de peixes de água doce do Espírito Santo", pretende-se contribuir para o conhecimento sobre a ictiofauna de água doce no Espírito Santo. O Projeto estuda os sistemas hídricos capixabas e vem realizando uma avaliação detalhada da ictiofauna de água doce do estado. Para efeito de sistematização deste estudo, as bacias do Espírito Santo foram reunidas em sete grupos: 1-A fauna de peixes das bacias do norte do Espírito Santo, incluindo as bacias dos rios Itaúnas e São Mateus; 2- A fauna de peixes das bacias do Rio Doce no Espírito Santo, incluindo as bacias dos rios Doce e Suruaca; 3- A fauna de peixes das bacias do nordeste do Espírito Santo, incluindo as bacias dos rios Riacho e Piraquê-Açu e as microbacias de Fundão e Aracruz; 4- A fauna de peixes das bacias do centro-norte do Espírito Santo, incluindo a bacia do rio Reis Magos e as microbacias de Serra (Sarmento-Soares \& MartinsPinheiro, 2010a); 5- A fauna de peixes das bacias do centrosul do Espírito, incluindo as bacias dos rios Santa Maria da Vitória e Jucu; 6 - A fauna de peixes das bacias do sudeste do Espírito Santo, incluindo as bacias dos rios Novo e Benevente e as microbacias de Guarapari. 7 - A fauna de peixes das bacias do sul do Espírito Santo, incluindo as bacias dos rios Itapemirim e Itabapoana e microbacias de Marataízes e Presidente Kennedy.

O Espírito Santo está situado na província Mantiqueira, unidade geotectônica pré-cambriana complexa, que se estende do centro-leste da Bahia até o sul do país, paralela à costa atlântica. A região sul e, por sua vez, toda a bacia do sudeste, situa-se dentro dos domínios do orógeno Araçuaí, que tem seus limites se estendendo do litoral atlântico até a borda leste do cráton São Francisco e entre os paralelos $15^{\circ}$ e $21^{\circ} \mathrm{S}$, fazendo divisa com o orógeno Ribeira na porção sul. Não há uma transição nítida entre os orógenos Ribeira e Araçuaí nesta porção sul do estado (Vervloet 2009).

A bacia do rio Benevente, a maior dos rios do sudeste, é também a de ocupação mais antiga. A foz do rio Benevente, onde se erguia a antiga aldeia de Reritiba, atual Anchieta, corresponde a uma das mais antigas missões jesuíticas do litoral do Espírito Santo (Magalhães \& Paraíso 2009). Ali, no século XVI, habitavam várias etnias indígenas, coletivamente chamadas de tupis. Imbuídos de admiração e repulsa, os sacerdotes da Companhia de Jesus deixaram os mais antigos relatos das populações nativas do nosso litoral (Magalhães \& Paraíso 2009). Ainda no século XVI, outro povoado, Guarapari, foi estabelecido para residência dos missionários jesuítas. Naquele tempo, havia ali uma antiga taba Goitacá, onde o Padre José de Anchieta teria feito erguer uma capela (Fausto 2000). Mais adiante, povos Puri, então habitantes do sul do Espírito Santo e norte do Rio de Janeiro, foram aldeados no baixo vale do Paraíba e na altura de Piúma (Freire \& Malheiros 2010). Apesar de hoje não haver mais aldeias no litoral sul capixaba, as ascendências indígenas, e também africanas, deixaram um marcante legado cultural por toda a região das baixadas litorâneas, do sul capixaba. Ali, predominam nos dias atuais, a atividade pesqueira e o turismo.

A região das cabeceiras, por outro lado, foi ocupada bem mais tarde. No Alto Rio Novo, fazendas escravocratas se instalaram no início da colonização portuguesa, por volta do século XVIII, para plantio do café. Escravos eram desembarcados no porto de Piúma. Muitas destas fazendas foram desativadas antes da chegada dos imigrantes. As famílias vindas da Europa, especialmente os italianos, subiram o rio Benevente ao final do século XIX, para o interior de Anchieta e Alfredo Chaves, onde se instalaram na produção agrícola. Uma parte dos imigrantes, fosse por receio de enchentes ou ataque de indígenas, deslocou-se para a região de Vargem Alta, Iconha e Rio Novo do Sul, ocupando altos e médios vales fluviais tanto do Benevente como do Rio Novo. Atualmente, nas encostas das montanhas, predomina a atividade agrícola, e muitas propriedades rurais se beneficiam das atividades de agroturismo e agroindústria. No vale do Rio Novo, destacase a extração de pedras ornamentais, como mármore e granito.

A Mata Atlântica na região dos rios do sudeste capixaba é composta por floresta ombrófila, floresta estacional semidecidual e formações pioneiras (brejos, restingas, mangues). O relevo nas cabeceiras fluviais é marcado pela zona serrana, formada por vales profundos e escavados, nos prolongamentos da Serra da Mantiqueira (Amorim 1984). A zona serrana foi intensamente explorada, onde se desenvolveu uma capoeira de regeneração, alta e com predomínio de imbaúbas (de Paula 2006). Nas terras baixas, predomina uma cobertura vegetal típica de restinga, além da formação de lagoas costeiras, que fornecem abrigo a uma fauna peculiar de peixes.

$\mathrm{O}$ presente trabalho teve como objetivo investigar a fauna de peixes das bacias sudeste do Espírito Santo, analisando as condições dos cursos d'água e a composição das espécies, sua distribuição espacial e endemismo nas bacias dos rios Novo, Benevente e nas microbacias de Guarapari.

\section{Material e Métodos}

Área de estudo. As bacias do sudeste do Espírito Santo possuem uma área cartográfica total de $2.366 \mathrm{~km}^{2}$, formada por quatro sistemas de bacias ou microbacias. A bacia do Rio Novo, ao sul, com $788 \mathrm{~km}^{2}$. As microbacias de Anchieta, entre as bacias dos rios Novo e Benevente, com $31 \mathrm{~km}^{2}$, compostas pelo córrego Iriri e pequenos riachos costeiros. A bacia do rio Benevente, com $1.096 \mathrm{~km}^{2}$, e as microbacias de Guarapari, com $450 \mathrm{~km}^{2}$ (Figura 1; Apêndice 1). As bacias do sudeste estão limitadas ao nordeste e sul pela bacia do rio Itapemirim, a noroeste e norte pela bacia do Jucu e a leste pelo Oceano Atlântico (Figura 2). Estão inseridas totalmente no Espírito Santo, fazendo parte da Região Hidrográfica do Atlântico Sudeste (CNRH 2003).

Regiões e pontos de amostragem. As bacias do sudeste do Espírito Santo foram aqui divididas em cinco regiões fisiográficas distintas: Cabeceiras do Rio Novo, Baixo Rio Novo, Cabeceiras do Benevente, Baixo Benevente e Microbacias de Guarapari. Foram averiguados 45 pontos georreferenciados em rios e córregos da região, sendo 13 na bacia do Rio Novo, 23 no rio Benevente e nove nas 


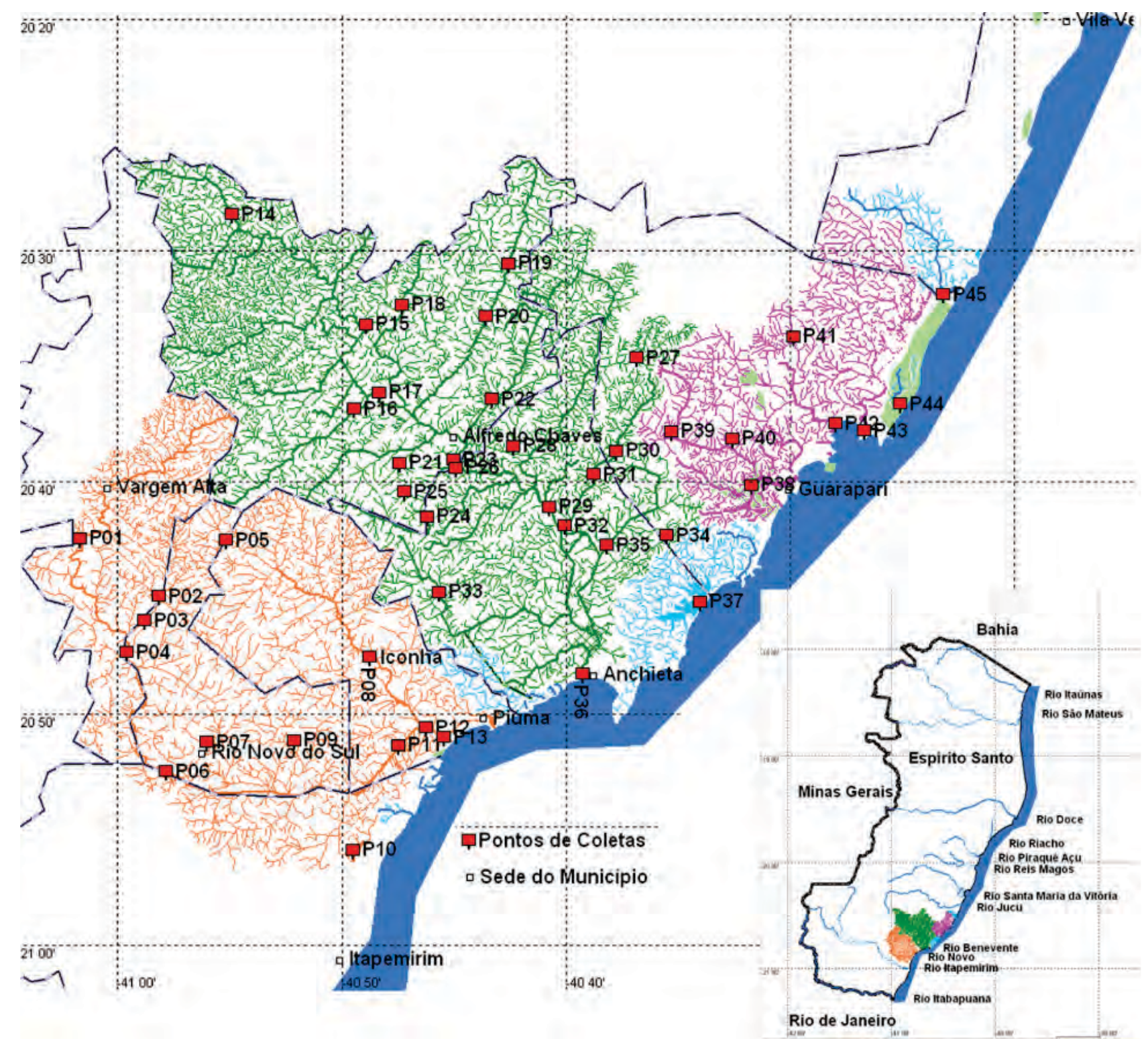

Figura 1. Mapa das bacias do sudeste do Espírito Santo: Rio Novo, rio Benevente e microbacias de Guarapari, indicando os limites dos municípios (linha tracejadas) e os 45 pontos de amostragem (P); para identificação e caracterização dos pontos, veja o Apêndice 2 e as Figuras 3-5

microbacias, nos municípios de Anchieta, Guarapari e Vila Velha (Figuras 1 e 3-5; Apêndice 2). As principais atividades econômicas nas bacias incluem a pecuária, a agricultura, e ainda extração de minério, o turismo e a pesca.

Rio Novo (P01-P13). O Rio Novo nasce na Serra do Richmond, na localidade de Ipeaçu, no município de Vargem Alta $\left(20^{\circ} 37^{\prime} 24.39^{\prime \prime S}\right.$ e $\left.40^{\circ} 54^{\prime} 33.57^{\prime \prime} \mathrm{W}\right)$, a uma altitude em torno de $800 \mathrm{~m}$. Seu principal afluente é o rio Iconha, que nasce da confluência de três rios: ribeirão Inhaúma, ribeirão Monte Alegre e o ribeirão São Pedro. Os rios Novo e Iconha seguem em diagonal, se aproximando um do outro até sua confluência, no município de Piúma, já na região das baixadas litorâneas, nas proximidades da foz do Rio Novo (2050'29.32"S e 4043'18.16”W). As águas da bacia do Rio Novo banham o município de Rio Novo do Sul, Iconha e parte dos municípios de Vargem Alta, Piúma e Itapemirim.
Cabeceiras do Rio Novo (P01-P05). Esta região hidrográfica foi definida com a região das nascentes formadoras dos rios Novos e Iconha, até o Baixo Rio Novo. Neste trecho de declividades acentuadas, o rio é torrencial e encachoeirado, com correnteza rápida e pedras. O principal contribuinte do Rio Novo no trecho superior é o ribeirão Concórdia, cuja confluência com o Rio Novo se dá já na divisa municipal com Rio Novo do Sul. O córrego Rodeio, afluente do ribeirão Monte Alegre, corresponde à nascente mais alta do rio Iconha, e nasce a uma altitude de $800 \mathrm{~m}$, na localidade de Princesa, em Rio Novo do Sul, também em um prolongamento da Serra do Richmond. Nas cabeceiras, os vales fluviais são ocupados principalmente pela lavoura de café e banana.

Baixo Rio Novo (P06-P13). A região hidrográfica do Baixo Rio Novo é delimitada pelo Rio Novo, abaixo da cota de $40 \mathrm{~m}\left(20^{\circ} 47^{\prime} 59^{\prime \prime} \mathrm{S}\right.$ e $\left.40^{\circ} 59^{\prime} 10^{\prime \prime} \mathrm{W}\right)$, e pelos afluentes que 


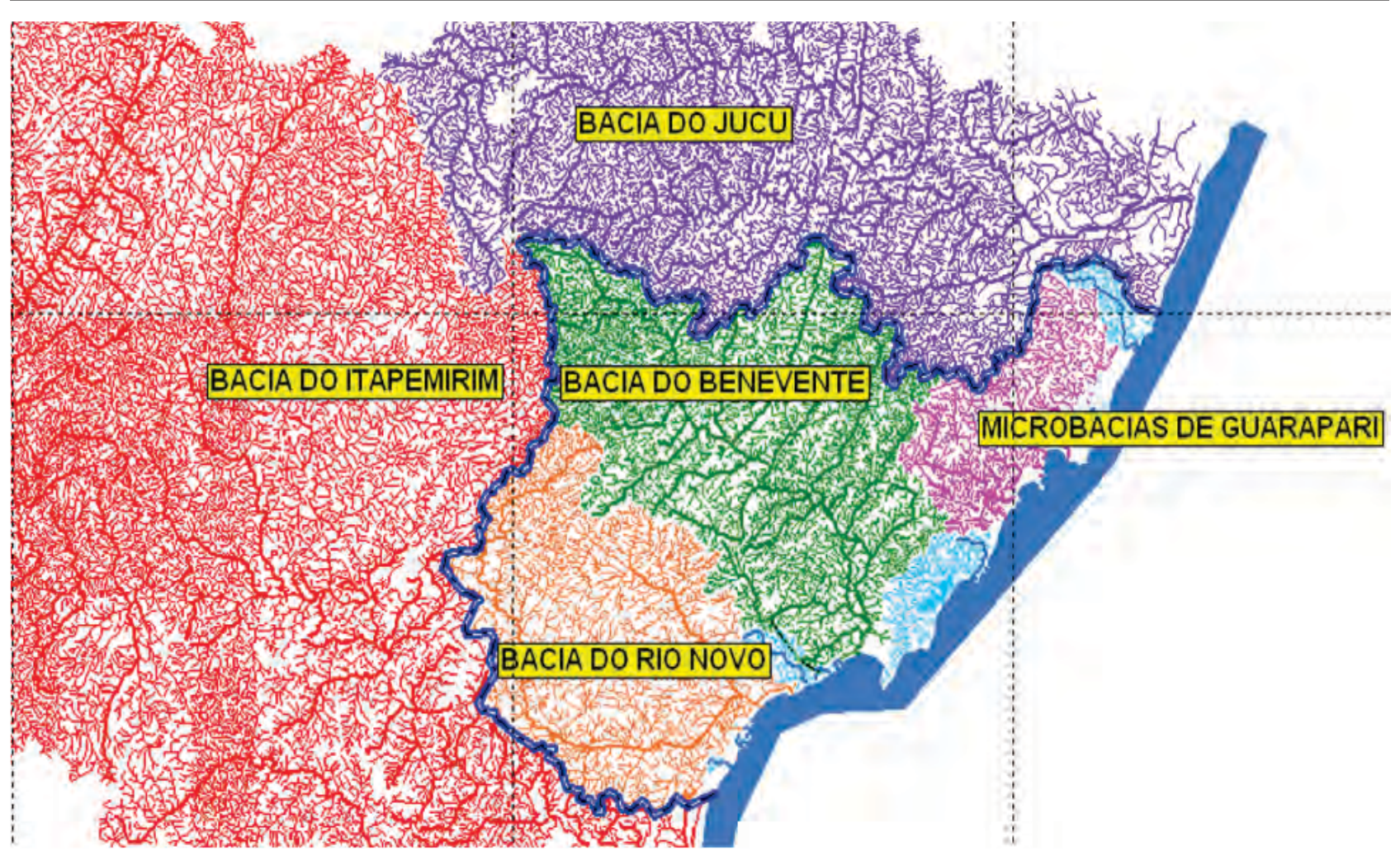

Figura 2. Mapa das bacias do sudeste do Espírito Santo, mostrando as bacias no entorno.

desembocam abaixo desta cota. A região formada pelo rio Iconha e seus afluentes abaixo da cota de $40 \mathrm{~m}\left(20^{\circ} 45^{\prime} 40^{\prime \prime} \mathrm{Se}\right.$ $\left.40^{\circ} 50^{\prime} 08^{\prime \prime} \mathrm{W}\right)$, também está incluída no Baixo Rio Novo. A declividade no terço inferior é mais suave, porém marcada por pequenos encachoeiramentos em determinados trechos. A baixa declividade facilitou a ocupação dos vales fluviais e neste trecho se encontram as cidades de Rio Novo do Sul e Iconha, às margens dos rios Novo e Iconha, respectivamente. Em seu baixo curso o Rio Novo forma uma ampla planície inundável, marcada por brejos e uma lagoa costeira com $0,6 \mathrm{~km}^{2}$, a lagoa Guanandy, no município de Itapemirim.

Rio Benevente (P14-P34). O rio Benevente nasce na Serra do Tamanco entre os municípios de Alfredo Chaves e Vargem Alta. As cabeceiras de drenagem que formam as nascentes principais deste rio encontram-se na região da Pedra do Alto do Redentor, após o distrito de Urânia, originando o Córrego do Redentor, que nas proximidades deste distrito, passa a receber o nome de rio Benevente (Vervloet 2009). Tem uma área de drenagem de aproximadamente $1.096 \mathrm{~km}^{2}$ e sua disponibilidade hídrica é estimada em $30 \mathrm{~m}^{3} / \mathrm{s}$. O rio Benevente percorre $84,5 \mathrm{~km}$ até desaguar em Anchieta e sua bacia banha os municípios de Anchieta, Alfredo Chaves e parte dos municípios de Iconha, Guarapari e Piúma (IEMA 2009).

Cabeceiras do Rio Benevente (P14-P20). Esta região hidrográfica foi definida com a região das nascentes formadoras do rio Benevente até o Baixo Rio Benevente. O rio Benevente surge da confluência do Córrego da Fortuna com o Córrego do Redentor, que nascem na Serra da Maravilha e na Serra do Redentor, a uma altitude de 1.120 e
$1.360 \mathrm{~m}$, respectivamente. Na parte mais alta da bacia, temos ainda o córrego São Bento, que deságua no Córrego da Fortuna, próximo à sua foz, e nasce em uma cota de 1.320 $\mathrm{m}$, o Córrego da Pedra, que nasce a $1.110 \mathrm{~m}$, e o córrego Alto Benevente, que nasce em uma cota de $1.090 \mathrm{~m}$ (Vervloet 2009). Seus principais contribuintes abaixo desta região de terras altas são: o ribeirão São Joaquim e os rios Iriritimirim, Batatal e Crubixá. A região das cabeceiras é marcada por trechos torrenciais e encachoeiramentos, a exemplo da Cachoeira da Matilde, um dos destinos turísticos mais procurados em Alfredo Chaves. O rio Benevente, em seu trecho superior, atravessa a cidade de Alfredo Chaves, onde recebe aporte de efluentes domésticos e lixo. Na região das cabeceiras do rio Benevente, no ribeirão São Joaquim, à montante da cidade de Alfredo Chaves, a Pequena Central Hidrelétrica (PCH) São Joaquim já está em operação para geração de energia, com capacidade instalada de $21 \mathrm{Mw}$ (SIGEL 2010). Há previsão de implantação de uma segunda PCH em Matilde, também no município de Alfredo Chaves (SIGEL 2010).

Baixo Rio Benevente (P21-P34). A região hidrográfica do Baixo Rio Benevente é delimitada pelo rio Benevente, antes da sede do município de Afonso Cláudio ( $20^{\circ} 38^{\prime} 00^{\prime \prime S}$, $40^{\circ} 45^{\prime} 05^{\prime \prime} \mathrm{W}$ ), e pelos afluentes que desembocam abaixo desta cota. Sua foz abriga um dos maiores manguezais do Espírito Santo, que penetra até 6,5 km da costa (Vale 2004). O manguezal do estuário do rio Benevente é um dos mais conservados do Espírito Santo. Contudo, alguns trechos deste manguezal sofreram erradicação da vegetação, pelo histórico de antropização da área (Pereira et al. 2009). Nas áreas mais internas do continente, os trechos de mangue são 


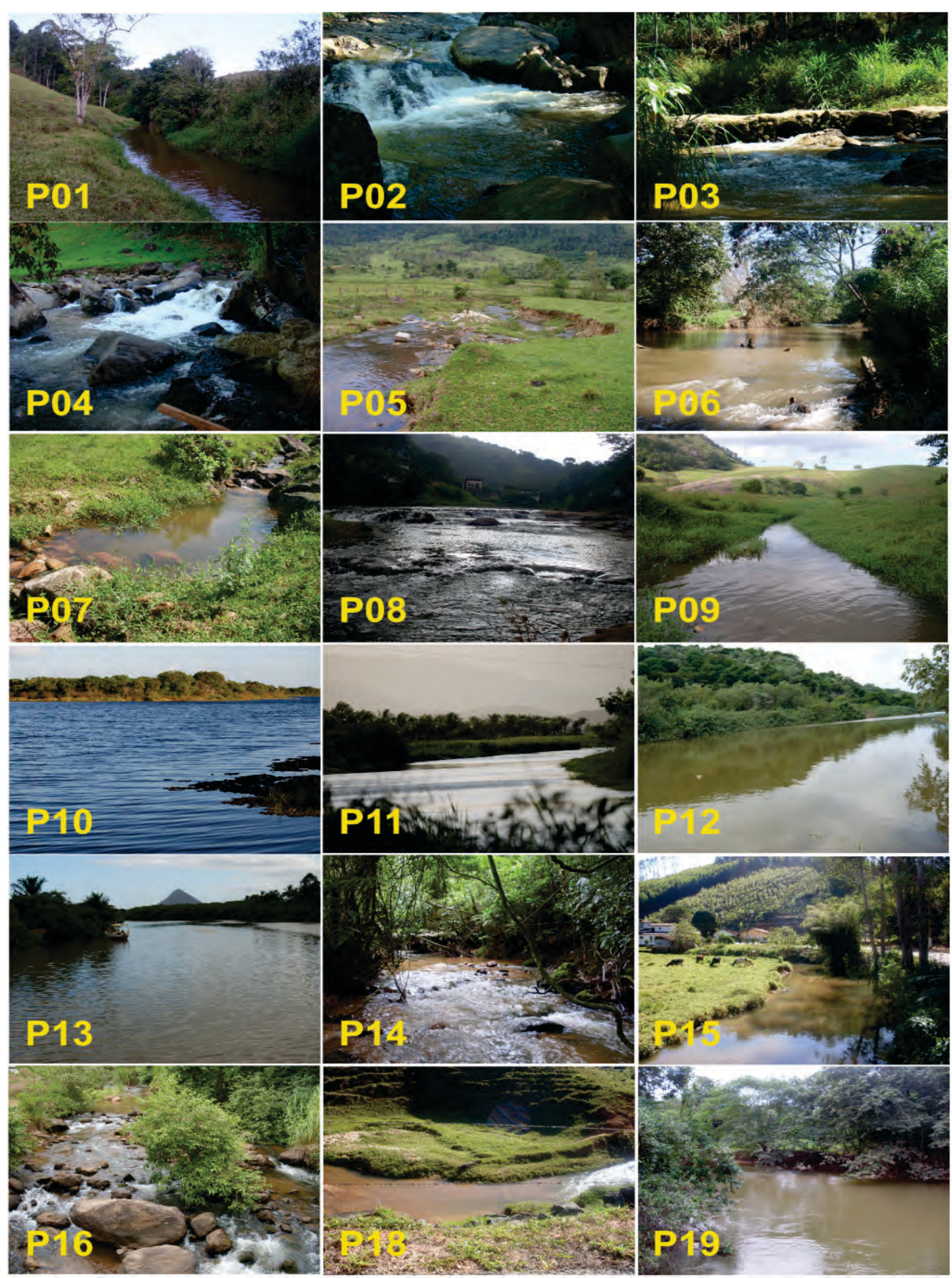

Figura 3. Pontos de amostragem (P) ao longo das bacias do sudeste do Espirito Santo; para identificação e caracterização dos pontos, veja o Apêndice 2 . 
maiores, onde há planícies inundáveis (Petri 2009). A principal forma de relevo desta região é a planície fluviomarinha, com predomínio de processos fluviais condicionados pela vazão fluvial do rio Benevente, e de seus afluentes nesta região como os rio Salinas, córrego Arerá e rio Pongal (Vervloet 2009). A pesca e a maricultura, com destaque para a mitilicultura e ostreicultura, são importantes atividades desenvolvidas junto à foz do Benevente (Vieira 2007).

Microbacias de Guarapari (P35-P45). Entre as bacias do rio Benevente e do rio Jucu, encontram-se as microbacias de Vila Velha, Guarapari e Anchieta. Ocupam $450 \mathrm{~km}^{2}$ de áreas de baixada, formando um conjunto de pequenas bacias litorâneas, com riachos contribuintes à Baía de Guarapari ou desaguando no Oceano Atlântico. O clima na baixada é Tropical Litorâneo, com temperaturas médias anuais em torno dos $23^{\circ} \mathrm{C}$, com estação quente e chuvosa de outubro a abril e estação fria e seca de maio a setembro. A Serra da Jaqueçaba, que separa as microbacias dos rios Jabuti e Benevente, está incluída nas unidades geológicas: Complexo Paraíba do Sul, Intrusivas Sin a Tarditangenciais e Depósitos Sedimentares, apresentando altitudes variando de 540 a $660 \mathrm{~m}$ (Burgos 2009). As microbacias de Guarapari estão distribuídas entre os municípios de Anchieta, Guarapari e Vila Velha, e abrigam pequenos córregos com extensões inferiores aos $20 \mathrm{~km}$. As planícies costeiras são ocupadas por mangues, lagoas, estuários ou baías com diferentes tipos de vegetação, variando desde formações herbáceas, arbustivas, e florestas. Nos alagados, a vegetação é predominantemente composta por taboais, Typha domingensis Pers. Os manguezais do estuário do rio Benevente e da Baía de Guarapari, estão entre os dez mais conservados do Espírito Santo, apesar do longo histórico de ocupação humana junto à foz (Vale \& Ferreira 1998; de Paula 2006; Pereira et al. 2009). A lagoa Mãe Bá é a maior da região, com $4 \mathrm{~km}^{2}$ de extensão. A microbacia do rio Una, entre Guarapari e Vila Velha, é a de maiores dimensões, com a nascente principal distante 19,8 km do Oceano. A microbacia do rio Churry é a única totalmente inserida no município de Vila Velha. A declividade suave em direção à costa permite a formação de numerosos alagados e várzeas. A localização destas microbacias em área de reconhecida beleza natural é vitimada pela intensa especulação imobiliária. Muitos ambientes para peixes encontram-se degradados, alvo de aterros e poluição. Esforços para preservação dos ambientes costeiros têm sido implementados regionalmente, e é nesta área onde estão concentradas três das quatro unidades de conservação presentes nas bacias sudeste, como será discutido mais adiante.

Amostragem. As atividades de campo foram realizadas durante o dia, pela manhã até o crepúsculo, cobrindo quatro ou cinco localidades por dia. As rotas de coletas do projeto foram estabelecidas com base nas regiões do estado menos amostradas nas diversas coleções consultadas. Os pontos de amostragem foram previamente planejados, levando-se em conta o acesso, inclusive as travessias por vias menores não pavimentadas. Os pontos de amostragem foram georreferenciados, fotografados e caracterizados quanto às condições ambientais. Foram ainda realizadas anotações sobre horário e artefatos de pesca empregados. As amostragens foram realizadas com o uso de puçás, picarés, "covos", rede de arrasto tipo trawl, redes de arrastos, tarrafa tipo argola, rede passaguá, tarrafa multifilamento e redes de espera. Em cada ponto, foi usada uma combinação dos recursos de pesca de forma a assegurar uma exaustiva amostragem de leito, fundo e margem. Cada localidade foi amostrada percorrendo-se um trecho de aproximadamente $50 \mathrm{~m}$ rio acima. Os exemplares coletados foram fotografados vivos, em aquário de campo, fixados em formalina a $10 \%$ e transportados para o laboratório, onde foram triados, transferidos para conservação em álcool a $70 \%$, identificados e catalogados. Informações históricas acerca da ictiofauna na região de estudo, foram obtidas a partir de consulta ao banco de dados do Sistema Brasileiro de Informações sobre Coleções Ictiológicas (NEODAT III) e do Centro de Referência em Informação Ambiental (CRIA).

Taxonomia. A classificação taxonômica dos exemplares seguiu Buckup et al. (2007), para peixes de água doce, e Carvalho Filho (1999) e Menezes et al. (2003), para peixes marinhos. O material coletado durante o projeto encontra-se depositado nas coleções ictiológicas do MBML (Museu de Biologia Professor Mello Leitão e do MNRJ), Museu Nacional e Universidade Federal do Rio de Janeiro. Informações das espécies amostradas na bacia e do material histórico depositado em coleções científicas aparecem em banco de dados (Sarmento-Soares \& Martins-Pinheiro 2010 $a, b)$.

Análise de dados. Os mapas georrefenciados dos rios foram peparados no Trackmaker v. Pro 4.6, com base nas cartas do IBGE de 1:100.000 e 1:50.000 e verificações de campo. Os resultados de comprimento e áreas cartográficos foram calculados com base nos mapas utilizando o mesmo programa. As coordenadas de campo de dados históricos, sem esta informação, estão baseadas em pesquisas, nos mapas elaborados neste estudo e nas informações de localidade disponível nos livros de tombo dos lotes. Para a elaboração dos mapas e tabelas, informações sobre pontos de coleta próximos foram agrupadas em um único ponto.

Para caracterizar a ictiofauna da bacia do Sudeste, foram utilizadas avaliações de constância, rarefação, riqueza, dominância, diversidade e uniformidade. Os valores de Constância de Ocorrência (C) das diferentes espécies foram calculados segundo Dajoz (1983). Como estimadores de riqueza, foram usados os índices de riqueza não-paramétricos Chao2, Jackknife1, Jackknife2 e Bootstrap. Para a obtenção da riqueza específica, foi utilizado o índice de riqueza de Margalef(M), que se baseia na relação entre o número de espécies identificadas e o número total de indivíduos coletados. A estimativa da diversidade foi realizada utilizando-se o Índice de ShannonWiener. A uniformidade ("equitability") foi calculada usando-se o índice de Pielou (1969). Os valores foram considerados conforme descrito em Sarmento-Soares et al. (2009). Para os diferentes índices e curvas, foi utilizado o PAST 2.03 (Palaeontological Statistics Software Package for Education and Data Analysis; Hammer et al. 2001). 


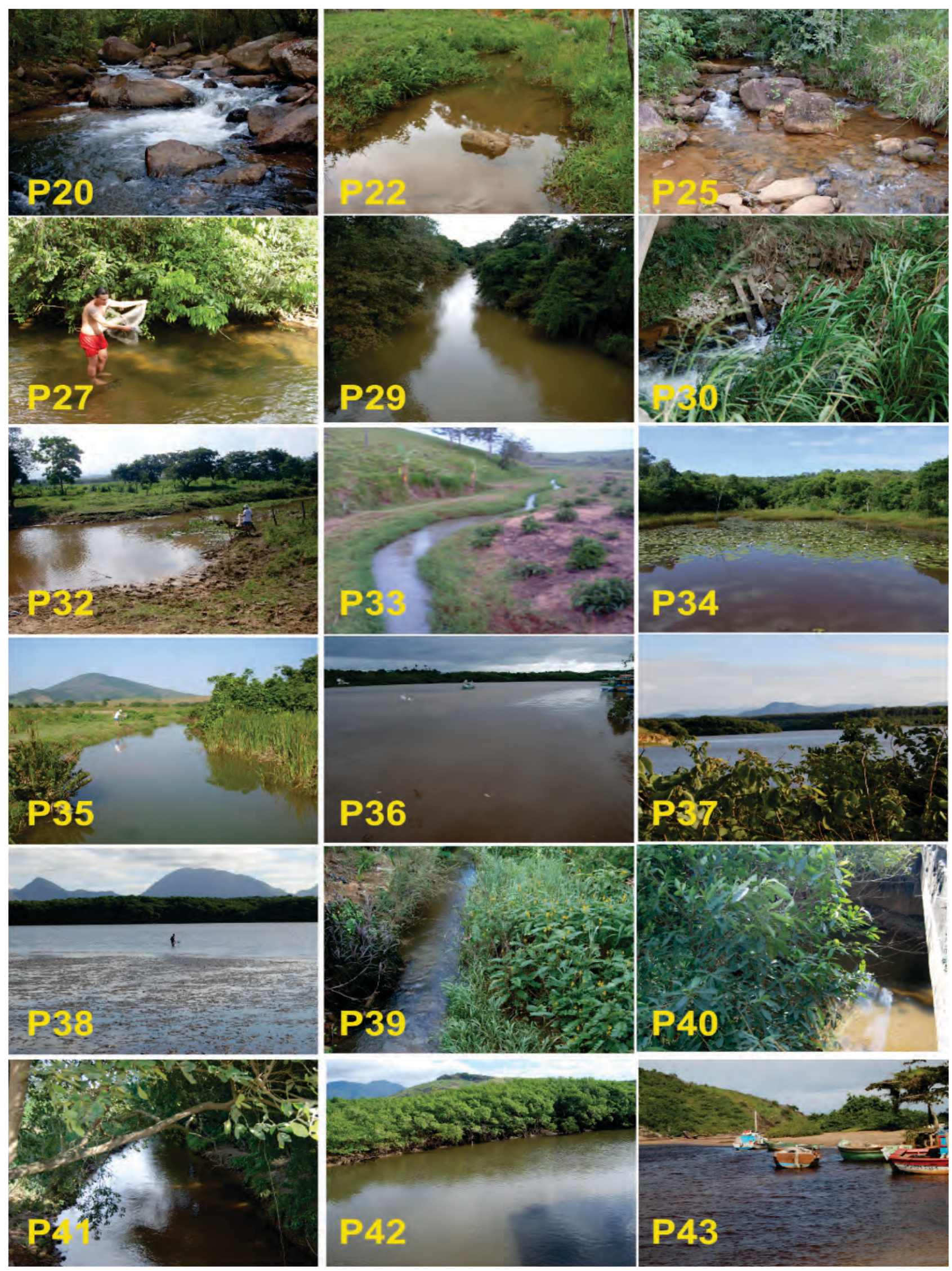

Figura 4. Pontos de amostragem (P) ao longo das bacias do sudeste do Espírito Santo; para identificação e caracterização dos pontos, veja o Apêndice 2. 


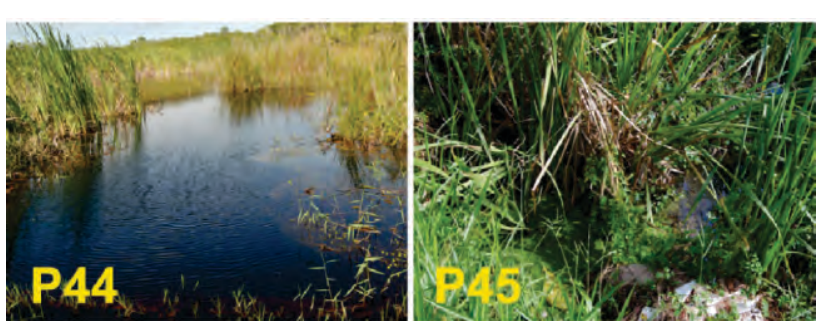

Figura 5. Pontos de amostragem (P) ao longo das bacias do sudeste do Espírito Santo; para identificação e caracterização dos pontos, veja o Apêndice 2

\section{Resultados}

Foram coletadas 110 espécies, pertencentes a 46 famílias e 17 ordens, com predominância dos Perciformes (42 espécies, 37,5\%; Apêndice 3; Material Suplmentar). Das espécies amostradas, 62 são estuarinas ou marinhas que frequentam o estuário. Entre as 47 espécies de água doce, predominaram peixes das ordens Characiformes e Siluriformes, com 16 espécies cada uma (34\%). As demais aparecem distribuídas entre os Perciformes, com 6 espécies em água doce (12,8\%), Cyprinodontiformes, com cinco espécies, sendo três introduzidas (10,6\%), Gymnotiformes, com três espécies $(6,4 \%)$, Synbranchiformes, com uma espécie (2,1\%). Foram encontradas 51 espécies na bacia do Rio Novo, sendo 20 estuarinas e marinhas (Apêndice 4), 46 espécies na do rio Benevente, sendo três estuarinas e marinhas (Apêndice 5) e 74 espécies nas microbacias de Guarapari, com 53 estuarinas e marinhas (Apêndice 6).

Espécies de porte médio a grande, como Prochilodus vimboides (Figura 6A) e Glanidium melanopterum, foram unicamente encontradas no rio Benevente. Peixes habitantes de águas torrenciais, como os migradores Prochilodus vimboides, Leporinus copelandii (Figura 6B) e Leporinus conirostris, e ainda cascudos, como Harttia loricariformis e Rineloricaria steindachneri, foram localizados no Benevente e/ou no Rio Novo. As espécies de água doce registradas nas microbacias de Guarapari foram em sua maioria peixes de pequeno porte, também encontrados nos ambientes de água doce do Rio Novo e Benevente. A única espécie de água doce restrita às microbacias de Guarapari foi Mimagoniates microlepis. As famílias com maior diversidade de espécies foram os Characidae, com 10 espécies, seguida dos Gobiidae, com nove espécies, e dos Loricariidae, com sete.

A única espécie considerada constante foi Geophagus brasiliensis (Figura 7Z), com presença em mais da metade dos pontos amostrados. Cinco espécies foram consideradas acessórias: Characidium sp. 1 aff. C. alipioi (Figura 6C), $A$. intermedius (Figura 6D), Astyanax sp. 1 aff. A. lacustris (Figura 6E), Deuterodon parahybae (Figura 6F) e Parotocinclus maculicauda (Figura 7O). As 104 espécies restantes foram reconhecidas como ocasionais. Dentre as espécies encontradas na região, seis ocorreram em todas as regiões fisiográficas: Characidium sp. 1 aff. C. alipioi, Astyanax sp. 1 aff. A. lacustris, A. giton (Figura 6G), Parotocinclus maculicauda, Rhamdia sp. e Geophagus brasiliensis. Outras 10 espécies ocorreram nas três bacias do sudeste: Astyanax janeiroensis, Deuterodon parahybae,
Hoplias malabaricus, Hyphessobrycon bifasciatus, Trachelyopterus striatulus, Hypostomus affinis (Figura $6 \mathrm{~N})$, Pimelodella pectinifer (Figura 7P), Poecilia vivipara, Microphis brachyurus, Cichla pinima. Dez espécies tiveram registros restritos à parte baixa do Rio Novo: Leporinus conirostris, Aspistor luniscutis, Mugil trichodon, Pseudophallus mindii, Centropomus undecimalis, Diapterus rhombeus, Eugerres brasilianus (Figura 7W), Dormitator maculatus, Guavina guavina e Evorthodus lyricus. Outras nove espécies ficaram limitadas ao baixo rio Benevente: Hoplerythrinus unitaeniatus, Callichthys callichthys (Figura 6J), Rineloricaria steindachneri, Imparfinis sp., Glanidium melanopterum (Figura 7Q), Xiphophorus hellerii, X. maculatus, Selene vomer e Ciclichthys spinosus. Quarenta espécies ficaram restritas às microbacias de Guarapari, sendo que apenas Mimagoniates microlepis não é de origem marinha. As regiões hidrográficas de cabeceiras compartilharam nove espécies: Astyanax intermedius, Phalloceros elachistos, Geophagus brasiliensis, Characidium sp.1 aff. C. alipioi, Astyanax sp. 1 aff. A. lacustris, Deuterodon parahybae, Parotocinclus maculicauda, Rhamdia sp. e Trichomycterus caudofasciatus (Figura 6I). Cinco espécies apareceram nas
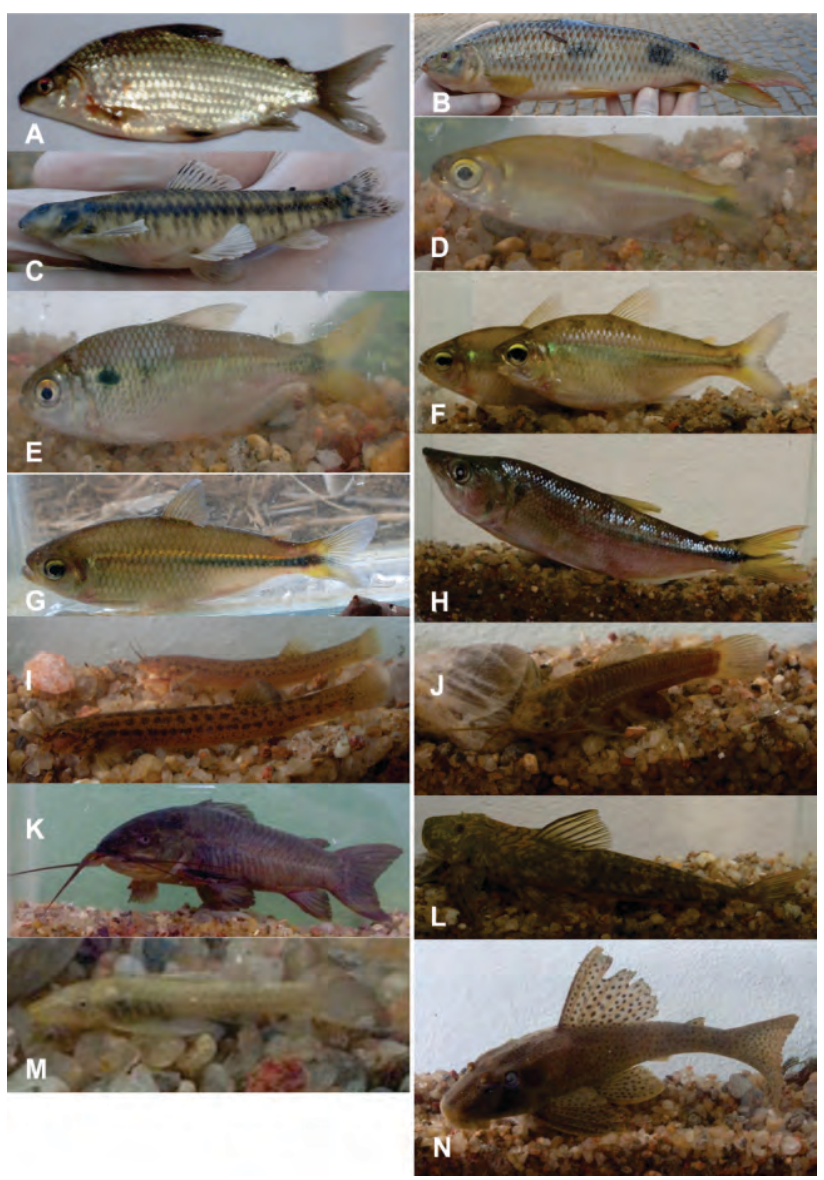

Figura 6. Espécies de peixes das bacias do sudeste do Espírito Santo: A-Prochilodus vimboides; B-Leporinus copelandii; C- Characidium sp. 1 aff. C. alipioi; DAstyanax intermedius; $\mathbf{E}$ - Astyanax sp. 1 aff. A. lacustris; F-Deuterodon parahybae; G- Astyanax giton; H- Oligosarcus acutirostris; I- Trichomycterus caudofasciatus; J-Callichthys callichthys; K- Hoplosternum littorale; L- Harttia loricariformis; MHisonotus sp.; $\mathbf{N}$ - Hypostomus affinis. 


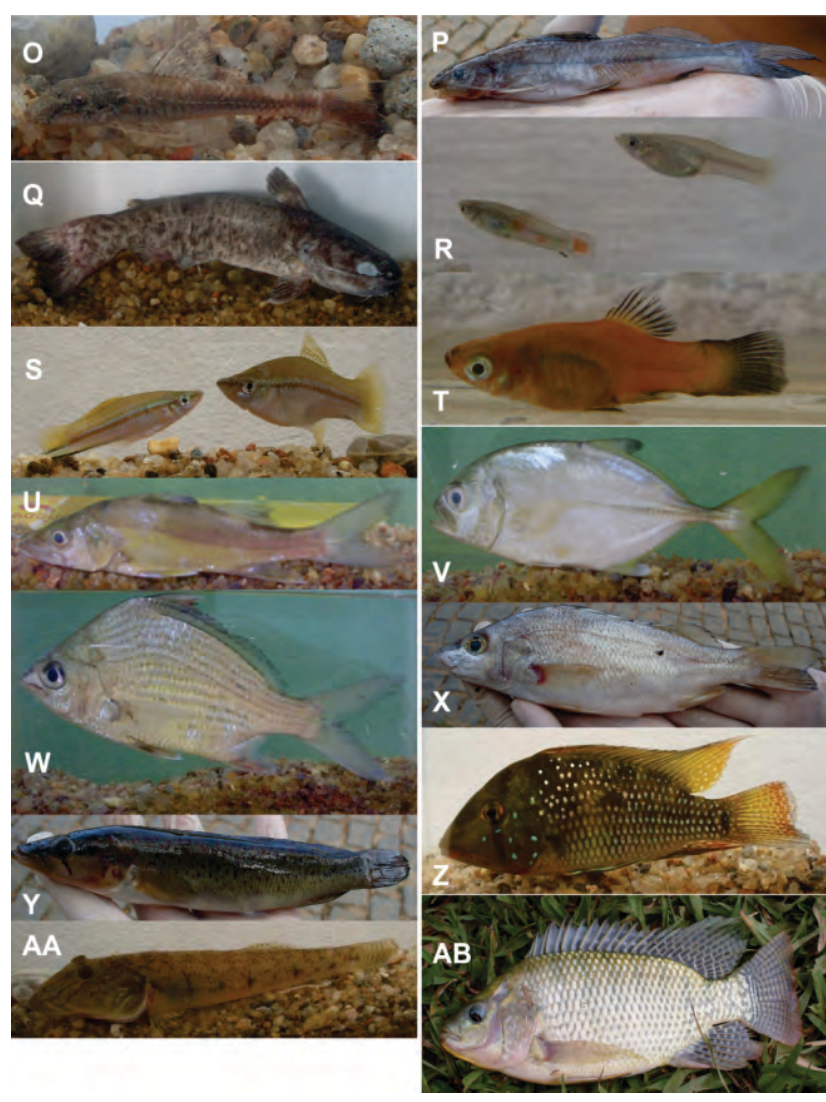

Figura 7. Espécies de peixes das bacias do sudeste do Espírito Santo: OParotocinclus maculicauda; P-Pimelodella pectinifer; Q- Glanidium melanopterum R- Poecilia reticulata macho e fêmea; $\mathbf{S}$ - Xiphophorus hellerii macho e fêmea; $\mathbf{T}$ Xiphophorus maculatus; $\mathbf{U}$-Centropomus parallelus; $\mathbf{V}$ - Caranx latus; $\mathbf{W}$ - Eugerres brasilianus; X-Pomadasys ramosus; Y- Crenicichla lacustris; Z- Geophagus brasiliensis; AA-Awaous tajasica; $\mathbf{A B}$ - Tilapia rendalli.

cabeceiras do Rio Novo, mas não foram encontradas nas cabeceiras do rio Benevente: Deuterodon parahybae, Crenicichla lacustris (Figura 7Y), Hypostomus affinis, Synbranchus marmoratus e Poecilia reticulata. Já nas cabeceiras do rio Benevente foram registradas 13 espécies não citadas para as cabeceiras do Rio Novo: Astyanax janeiroensis, A. giton, Pimelodella pectinifer, Poecilia vivipara, Tilapia rendalli, Leporinus copelandii, Oligosarcus acutirostris (Figura 6H), Otothyris lophophanes, Gymnotus carapo, Awaous tajasica (Figura 7AA), Prochilodus vimboides, Australoheros muriae e Harttia loricariformis (Figura 6L).

Os peixes mais numerosos na bacia do Sudeste do Espírito Santo pertencem a Astyanax spp., com quatro espécies na área. Astyanax giton teve a distribuição restrita a uma única bacia, a do rio Benevente. Foi encontrada especialmente nos trechos altos, encachoeirados. Astyanax intermedius teve sua ocorrência associada aos trechos de cabeceira, com um único registro para a parte baixa da bacia do Benevente, no Rio Grande. Estas espécies são aparentemente substituídas por A. janeiroensis, forma mais comum nas baixadas litorâneas. Por outro lado, Astyanax sp. 1 aff. A. lacustris, apareceu em todas as bacias, ao longo dos diversos gradientes longitudinais, especialmente associada a ambientes lênticos. Várias das espécies de Astyanax tiveram registro de distribuição sintópica, como
A. janeiroensis, Astyanax sp.1 aff. A. lacustris e/ou $A$. intermedius.

O sarapó Gymnotus carapo foi localizado ao longo do gradiente longitudinal dos rios do sudeste, nas bacias dos rios Novo e Benevente, em ambiente com vegetação marginal de gramíneas, onde estes peixes se ocultam. Por outro lado, a espécie congênere $G$. pantherinus ficou limitada às baixadas litorâneas do rio Benevente e microbacias de Guarapari. Gymnotus pantherinus foi encontrada em ambientes aquáticos com acumulação de turfa (J.L. Helmer, com. pess.), onde se abrigam sob extensos tapetes verdes, formados por raízes e estolões de macrófitas aquáticas. Ambas as espécies foram registradas sintopicamente no Rio Grande (P31). Awaous tajasica, um Gobiidae restrito as águas salobras e doces, foi localizada apenas na bacia do rio Benevente, tanto na parte baixa como nas cabeceiras, tendo um lote sido registrado no rio Batatal, a 340 m de altitude (P20).

Das 54 espécies marinhas encontradas nas bacias do sudeste do Espírito Santo, 35 apareceram unicamente nas microbacias de Guarapari. Esta enorme proporção de espécies de origem marinha nestas microbacias era esperada pelo tipo de ambiente favorável e a própria dimensão da baía de Guarapari, que favorecem a entrada de peixes marinhos. Para o Baixo Rio Benevente, foram registradas apenas duas espécies marinhas e uma estuarina, indicando que para muitas espécies, a entrada em ambiente de água doce é ocasional. Das espécies marinhas encontradas, algumas têm valor comercial, como Lutjanus jocu, Pomadasys ramosus (Figura 7X) e Mugil spp., e frequentam os manguezais da região, seja nas fases iniciais de desenvolvimento ou mesmo na fase adulta. Centropomus parallelus (Figura 7U) e Centropomus undecimalis transitam nos dois ambientes, sendo encontrado habitualmente nas partes baixas das bacias. No rio Benevente, foram registrados espécies marinhas até a altura do rio Joéba (P23). Pescadores de Alfredo Chaves relataram que costumam descer o rio até Jabaquara (P27), em busca de espécies comerciais de maior porte de origem marinha, como o robalo e a corvina, que adentram o rio Benevente.

Algumas espécies exóticas também foram registradas. O tucunaré Cichla pinima, nativo dos tributários ao sul do Amazonas, foi registrado na parte baixa das três bacias, em algumas lagoas costeiras, como nas lagoas Mãe Bá e Guanandy, e ainda em córrego costeiro no contorno de Guarapari. A tilápia (Tilapia rendalli; Figura 7AB), nativa da África, foi encontrada no terço médio do rio Benevente e também na lagoa Mãe Bá. Através de depoimentos de pescadores ribeirinhos e fotos, foram registradas outras espécies exóticas como o bagre africano Clarias gariepinnus, que possivelmente se espalhou pelo terço médio e baixadas litorâneas, sendo desconhecida sua ocorrência à montante de Alfredo Chaves. Pequenos Cyprinodontiformes, conhecidos como barrigudinhos (Poecilia reticulata; Figura 7R), e ainda duas espécies de peixe-espada, Xiphophorus helleri (Figura 7S) e $X$. maculatus (Figura 7T), foram encontrados nas cabeceiras do rios Novo e Benevente, respectivamente. Moradores ribeirinhos cultivam o peixe-espada como espécie ornamental

Sitientibus série Ciências Biológicas 12(1): 1-25. 2012. 
Tabela 1. Estimativa não-paramétrica de riqueza de espécies e descritores da ictiofauna nas bacias do sudeste do Espírito Santo (com e sem a presença dos peixes marinhos). CRN- Cabeceiras do Rio Novo (Pontos 1 a 5); BRN- Baixo Rio Novo (Pontos 6 a 13); RN- Bacia do Rio Novo (Pontos 1 a 13); CRBCabeceira do Rio Benevente (Pontos 14 a 20); BRB- Baixo Rio Benevente (Pontos 21 a 34); BN- Bacia do Benevente (Pontos 14 a 34); MG- Microbacias de Guarapari (Pontos 35 a 45); BSU- Bacias do Sudeste (Ponto 1 a 45). Para identificação e caracterização dos pontos, veja o Apêndice 2 e as Figuras 3 -5.

\begin{tabular}{|c|c|c|c|c|c|c|c|c|}
\hline \multicolumn{9}{|c|}{ COM MARINHOS } \\
\hline Estimadores & CRN & BRN & $\mathbf{R N}$ & CRB & $\overline{\text { BRB }}$ & BN & MG & $\overline{\text { BSU }}$ \\
\hline Chao 2 & 20,3 & 114,2 & 80,1 & 44,3 & 58,1 & 62,4 & 216,0 & 170,0 \\
\hline Jackknife 1 & 19,4 & 82,5 & 79,8 & 35,9 & 60,9 & 64,2 & 130,5 & 161,9 \\
\hline Jackknife 2 & 22,9 & 103,7 & 93,4 & 44,2 & 67,5 & 71,8 & 171,5 & 191,0 \\
\hline Bootstrap & 15,9 & 64,3 & 65,0 & 28,5 & 53,0 & 56,0 & 97,8 & 133,8 \\
\hline \multicolumn{9}{|l|}{ Descritores } \\
\hline Espécies coletadas (S) & 13 & 51 & 53 & 23 & 46 & 49 & 75 & 112 \\
\hline Exemplares (n) & 192 & 568 & 760 & 342 & 3.387 & 3.729 & 700 & 5.189 \\
\hline Dominância (D) & 0,39 & 0,05 & 0,06 & 0,12 & 0,14 & 0,12 & 0,06 & 0,08 \\
\hline Diversidade Shannon $(\mathrm{H})$ & 1,39 & 3,32 & 3,27 & 2,46 & 2,42 & 2,61 & 3,31 & 3,19 \\
\hline Riqueza Margalef (M) & 2,28 & 7,88 & 7,84 & 3,77 & 5,54 & 5,84 & 11,30 & 12,98 \\
\hline Uniformidade (e) & 0,54 & 0,84 & 0,82 & 0,79 & 0,63 & 0,67 & 0,77 & 0,68 \\
\hline \multicolumn{9}{|c|}{ SEM MARINHOS } \\
\hline Estimadores & CRN & $\overline{\text { BRN }}$ & $\mathbf{R N}$ & CRB & BRB & BN & MG & BSU \\
\hline Chao 2 & 20,3 & 64,0 & 45,1 & 44,3 & 50,9 & 54,7 & 48,0 & 58,6 \\
\hline Jackknife 1 & 19,4 & 54,3 & 50,8 & 35,9 & 55,1 & 58,4 & 42,4 & 63,8 \\
\hline Jackknife 2 & 22,9 & 66,3 & 54,2 & 44,2 & 59,1 & 63,3 & 52,7 & 64,0 \\
\hline Bootstrap & 15,9 & 43,3 & 43,9 & 28,5 & 48,9 & 51,9 & 33,0 & 59,8 \\
\hline \multicolumn{9}{|l|}{ Descritores } \\
\hline Espécies coletadas (S) & 13 & 35 & 37 & 23 & 43 & 46 & 26 & 55 \\
\hline Exemplares (n) & 192 & 424 & 616 & 342 & 3.384 & 3.726 & 449 & 4.791 \\
\hline Dominância (D) & 0,39 & 0,07 & 0,08 & 0,12 & 0,14 & 0,12 & 0,13 & 0,09 \\
\hline Diversidade Shannon $(\mathrm{H})$ & 1,39 & 2,92 & 2,91 & 2,46 & 2,42 & 2,61 & 2,40 & 2,89 \\
\hline Riqueza Margalef (M) & 2,28 & 5,62 & 5,61 & 3,77 & 5,17 & 5,47 & 4,09 & 6,37 \\
\hline Uniformidade (e) & 0,54 & 0,82 & 0,80 & 0,79 & 0,64 & 0,68 & 0,74 & 0,72 \\
\hline
\end{tabular}

As estimativas de riqueza de espécies para as bacias sudeste do Espírito Santo, incluindo-se as espécies marinhas, apresentaram uma variação de $42,4 \%$ entre o valor maior calculado pelo método Jackknife2 $(187,1)$ e o menor valor obtido pelo método Bootstrap $(131,4)$. Excluindo-se as espécies marinhas a variação foi de apenas $8,8 \%$ entre os resultados pelo método Jackknife $2(55,0)$ e o método Chao2 $(50,6)$. Em ambos os casos as estimativas com os demais métodos apresentaram valores intermediários (Tabela 1). Os métodos utilizados sugerem então, excluindo-se as espécies marinhas, um aumento máximo de sete espécies além das 47 espécies de água doce registradas para a bacia.

As avaliações dos índices paramétricos mostram uma variação significativa, quando se consideram as espécies marinhas para as regiões fisiográficas das cabeceiras do Rio Novo e das Microbacias de Guarapari, refletindo a elevada presença de espécies marinhas nesta microbacia. Nas demais regiões fisiográficas, os índices se mantiveram próximos. A variação na bacia produziu uma diferença de $129 \%$ no índice de Margalef (5,56 considerando apenas as espécies dulcícolas versus 12,74 considerando todas as espécise) e de 13\% no índice de Shanon (2,81 versus 3,17).

\section{Discussão}

Biogeografia. A fauna de peixes de água doce da América do Sul, composta principalmente de peixes primariamente de água doce, como os Ostariophysi, possui sua história evolutiva principal ligada à história geológica, quando os sistemas hídricos no continente foram formados e modificados (Lundberg et al. 1998; Castro 1999). Ribeiro (2006) sugere que a fauna endêmica das drenagens costeiras brasileiras teria se diversificado no Cretáceo. No entanto, ainda há poucos estudos de abrangência regional, em escala intracontinental. A região hidrográfica do Atlântico Sudeste é formada por numerosos rios que deságuam no Oceano Atlântico. Dentro desta região hidrográfica, a bacia do Rio Doce e a bacia do rio Paraíba do Sul são os maiores sistema fluviais. Comparadas a sistemas vizinhos, as bacias do sudeste do Espírito Santo são pequenas, estando encaixadas entre as bacias dos rios Itapemirim e Jucu. Muitas das espécies de peixes de água doce reconhecidas para as bacias fluviais do sudeste do Espírito Santo coincidem com as encontradas no baixo curso do rio Paraíba do Sul, entre Muriaé e Campos, no norte fluminense. O rio Paraíba do Sul, dentro de províncias geográficas distintas, apresenta 
um elevado grau de endemismo para peixes de água doce, influenciando regionalmente drenagens vizinhas (Ab'Sáber \& Bernardes 1958; Bizerril et al. 1998). Do ponto de vista geológico, processos erosivos na margem leste do sudeste do Brasil parecem ter introduzido uma movimentação da fauna aquática, transferindo estoques ancestrais de peixes das terras altas para os rios de baixada (Ribeiro 2006). No final do Pleistoceno, com o rebaixamento do nível do mar, houve subsequente dispersão da fauna aquática, ampliando a área de distribuição de muitas espécies ao longo das drenagens costeiras. Para certas espécies de peixes, com distribuição geográfica compartilhada com o Baixo Paraíba do Sul, os rios do sudeste do Espírito Santo parecem representar seu limite norte de distribuição de um conjunto de espécies com endemismo regional. Aparentemente, esta é a situação de Deuterodon parahybae, Harttia loricariformis, Rineloricaria steindachneri, Pimelodella pectinifer e ainda Gymnotus pantherinus. Estas espécies são substituídas por congêneres em sistemas hídricos mais ao norte. A história biogeográfica das espécies de peixes de riacho das drenagens costeiras de Mata Atlântica está em grande parte relacionada à província geotectônica da Mantiqueira, palco de uma longa e complexa evolução biogeográfica, e tal história necessita maiores investigações.

Riqueza e Diversidade. As análises de riqueza e de diversidade são atualmente muito difundidas (Moreno 2001; Santos 2003). A interpretação de seus resultados auxilia na orientação de políticas públicas e nãogovernamentais de projetos conservacionistas. A forma mais empregada como medida de diversidade é a riqueza de espécies, que consiste simplesmente no número de espécies existente na área de estudo. $\mathrm{Na}$ maioria das vezes, não temos métodos que possam garantir que todas as espécies existentes foram capturadas; assim, o uso do índice de Margalef proporciona uma melhor indicação, pois considera além do número de espécies o total de indivíduos capturados. Os índices de diversidade de Shanon-Wiener e Simpson possuem uma vantagem em relação ao índice de Margalef, por considerarem também a proporção do total de ocorrência de cada espécie. Os índices de Shannon $\left(\mathrm{H}^{\prime}\right)$ e de Simpson diferem basicamente no peso em que se dá para espécies raras. No caso do Índice de Shannon, o peso é intermediário e, no índice de Simpson, o peso de espécies raras é pequeno. Optamos por este conjunto de índices para permitir uma caracterização mais ampla da bacia.

O elevado valor para o índice de Margalef para as microbacias de Guarapari deve-se ao grande número de espécies marinhas nesta região com forte presença estuarina. Os índices de riqueza excessivamente baixos na região de cabeceiras do Rio Novo podem estar vinculados ao menor número de coletas na região, indicando a necessidade de ampliá-las em futuros trabalhos.

Espécies com necessidade de revisão. Seis espécies referenciadas para a área possuem status taxonômico ainda indefinido: Hisonotus sp., Imparfinis sp., Astyanax sp.1 aff. A. lacustris, Characidium sp. 1 aff. C. alipioi, Rhamdia sp. e Eigenmannia sp. As espécies Hisonotus sp. e Imparfinis sp. são potencialmente novas e estão sendo investigadas por um dos autores (LMSS). Muitas espécies não identificadas no nível de espécie, contudo, pertencem a grupos taxonômicos complexos e podem representar novos táxons.

Astyanax está entre os gêneros mais comuns, porém menos compreendidos, de peixes de água doce na América do Sul (Melo 2005). Nos rios do sudeste foram reconhecidas quatro espécies de Astyanax; uma destas não foi formalmente descrita e é considerada potencialmente nova. Astyanax sp. 1 aff. A. lacustris, com mancha humeral ovalada conspícua e mancha escura no pedúnculo caudal estendendo-se até a extremidade dos raios caudais medianos, pertence ao grupo Astyanax bimaculatus (sensu Eigenmann 1921). Espécies de piabas do grupo $A$. bimaculatus são extremamente comuns nas bacias hidrográficas neotropicais, e apresentam grande plasticidade ecológica, o que aumenta as dificuldades de estudos (V. Garutti, com. pess). Garutti \& Britski (2000) indicam que as formas do grupo $A$. bimaculatus são portadoras de dente maxilar e padrão reticulado de cromatóforos, ocorrendo na bacia Amazônica e ao norte. Astyanax sp. 1 aff. A. lacustris não apresenta dentes no maxilar e não possui colorido reticulado (sensu Britski et al. 1986 e Garutti 1995), tendo sido associada a A. lacustris pela ausência de dentes no maxilar e mancha escura no pedúnculo caudal estendendo-se até a extremidade dos raios caudais medianos. Difere desta pelo par de dentes na sínfise mandibular simétricos, os olhos próximos ao focinho, e faixa prateada conspícua nos lados do corpo.

Characidium sp. 1 aff. C. alipioi foi associada a $C$. alipioi (Travassos 1955), pela semelhança no padrão de colorido e pela contagem de raios e escamas na linha lateral (cf. Travassos 1955). Distingue-se daquela espécie pelas proporções corporais e por apresentar 7 ou 8 dentes no dentário (vs. 9 ou 10). Characidium é o grupo mais especioso dentre os Crenuchidae e inclui muitas espécies por serem descritas ou pobremente diagnosticadas (Buckup 1993; Centofante et al. 2003). Endemismos para espécies ainda não descritas de Characidium têm sido levantados para rios de Mata Atlântica no extremo sul da Bahia (e.g., Sarmento-Soares et al. 2008, 2009), indicando a necessidade de estudos revisivos para este gênero.

Rhamdia quellen (Quoy \& Gaimardi, 1824), conhecida para as Américas, é assinalada para a grande maioria das bacias sul-americanas. As populações de Rhamdia do sudeste do Espírito Santo diferenciam de Rhamdia quellen (cf. Silfvergrip 1996: 95) pelo pedúnculo caudal em média $40 \%$ mais baixo no comprimento do pedúnculo (vs. 60,7\%), diâmetro do olho 15-17\% menor que o comprimento da cabeça (vs. 22,3\%). Rhamdia quelen foi descrita a partir de exemplares da Amazônia, no Peru, e perfaz um grupo bastante complexo. Verificamos que a população dos rios do Sudeste não se encaixa na diagnose da espécie e, assim, optamos por identificar a espécie local apenas no nível de gênero.

O gênero Eigenmannia Jordan \& Evermann é endêmico da América do Sul, com distribuição em diversas bacias hidrográficas continentais (Campos da Paz 1997; Silva et al. 2008), sendo comumente encontrado em ambientes de águas pouco profundas, até $3 \mathrm{~m}$. Muitas espécies carecem 
de identificações precisas e aparentemente existem várias espécies de Eigenmannia nativas da Mata Atlântica (Menezes et al. 2007). O reconhecimento das populações de Eigenmannia na região hidrográfica Atlântico Sudeste é precário e necessita ser revisado.

Espécies introduzidas. As lagoas costeiras do litoral sul do Espírito Santo são caracterizadas pela pouca profundidade e superfície entrecortada. Com suas águas lênticas, representam importantes ecossistemas aquáticos, fornecendo ambiente favorável para várias espécies da biota aquática, especialmente peixes. Uma potencial ameaça aos ambientes aquáticos é a introdução de espécies exóticas. Nas lagoas Mãe Bá e Guanandy, foram encontradas espécies exóticas, como o tucunaré Cichla pinima e a tilápia Tilapia rendalli, peixes que se disseminam facilmente em ambientes lacustres. Diversos estudos têm apontado impactos negativos sobre as comunidades nativas de peixes diante da presença de espécies exóticas invasoras (e.g., Canonico et al. 2005; McCrary et al. 2006; Athayde et al. 2007; Vitule et al. 2008). Aspectos negativos da presença de espécies invasoras em ambientes naturais podem incluir mudanças na estrutura da vegetação e perturbações nas comunidades de peixes nativos, com consequente redução dos estoques de certas espécies e ainda a supressão de outras (Latini \& Petrere 2004; McCrary et al. 2006). Porém, nem todas as introduções de espécies são deletérias para a ictiofauna nativa. Situações de introduções bem sucedidas foram reportadas para o tucunaré Cichla piquiti no Pantanal (e.g., Resende et al. 2008). Por outro lado, estudos apontam que introduções de tilápia podem não trazer benefícios sócioeconômicos para a população ribeirinha (e.g., Dias 2006). Deve haver cautela quanto às introduções de espécies, pois uma vez estabelecidas, a situação geralmente é irreversível. Em muitos sistemas lacustres os impactos ambientais oriundos da introdução de espécies exóticas ainda permanecem pouco compreendidos (Athayde et al. 2007). No caso das lagoas nos rios do Sudeste, Mãe Bá e Guanandy, são recomendáveis estudos e monitoramentos a fim de verificar a distribuição das espécies introduzidas e avaliar os possíveis impactos sobre a fauna nativa.

Conservação. As unidades de conservação nas bacias do sudeste são todas litorâneas: a APA Guanandy, na bacia do Rio Novo, a RDS Concha da Ostra, o Parque Estadual Paulo Cesar Vinha e a APA Setiba, nas microbacias de Guarapari. AAPA Guanandy abriga a bela lagoa Guanandy, também conhecida como Lagoa das Sete Pontas devido a seu formato sinuoso. A lagoa Guanandy abriga um grande número de pequenos peixes, incluindo espécies ameaçadas, como Spintherobolus broccae, registrada em 1986 (J.L. Helmer, com. pess.), e que está na lista nacional de aquáticos ameaçados (MMA, 2004). Está espécie, no entanto, não foi localizada por nós durante os trabalhos de campo e nem nos registros das coleções consultadas. $\mathrm{O}$ Parque Estadual Paulo Cesar Vinha, preserva uma importante área de baixada litorânea, ao norte da cidade de Guarapari. Abriga os sistemas das lagoas Caraís, Feia e
Vermelha, além de um conjunto de áreas de brejo a elas associadas, formando uma grande planície inundável (CEPEMAR 2007). Aquele foi um dos poucos locais em toda a área de estudo onde Mimagoniates microleps, uma espécie típica das baixadas litorâneas que habita águas escuras e ácidas, foi encontrada. Um conjunto de 22 espécies de peixes foi referenciado para o Parque Paulo César Vinha no plano de manejo da unidade (CEPEMAR 2007). Dentre estas, nove espécies são de água doce, e somente Hyphessobrycon reticulatus não foi encontrado por nós na área de estudo. Como não há referência de depósito em coleções científicas no plano de manejo citado, não foi possível examinar tais espécimes.

O crescimento desordenado trazido pelo turismo pode ser observado no litoral capixaba de Guarapari e Anchieta, onde a população se torna quatro ou cinco vezes maior nas épocas de veraneio, pelo aporte de turistas. Com a balneabilidade das praias cada vez mais comprometida pela descarga de esgoto in natura, as cidades costeiras com vocação para o turismo são exemplos acabados dos impactos provocados pelo mercado imobiliário (Correia \& Leão 2006). O rio Meiaípe, em Guarapari, é um indicativo local da situação de degradação de manancial hídrico, onde há grande concentração de poluentes orgânicos e esgoto. Apesar de visitado por nós, a localidade se mostrou inviável para trabalhos de campo. Os impactos da ação antrópica fazem com que a maioria das lagoas litorâneas e banhados se encontre ameaçadas, cedendo lugar a empreendimentos imobiliários e à extração de areia para construções (Pompêo \& Moschini-Carlos 2010). Neste sentido, as unidades de conservação são de extrema importância para a preservação destes ambientes costeiros.

\section{Agradecimentos}

Queremos deixar nossos agradecimentos aos colegas da Zoologia do Museu de Biologia Prof. Mello Leitão (MBML); à equipe do Setor de Ictiologia do Museu Nacional/UFRJ e ao Laboratório de Ictiologia, Departamento de Oceanografia (CIUFES), pela cordialidade durante as visitas; Maria Margareth C. Roldi, Raphael Becalli Soares e Rogério L. Teixeira, pelo empenho e ajuda durante os trabalhos de campo e/ou laboratório; ao pescador Gilnem José, pelas informações sobre os peixes da região; a J.L. Helmer, L.R. Malabarba e V. Garruti, pela valiosa troca de ideias sobre algumas das espécies na área de estudo; a Marcelo R. Britto, pela identificação dos Callichthyidae; ao Parque Estadual Paulo César Vinha pelo uso da biblioteca e pela autorização dos trabalhos de registro visual e fotográfico dentro dos limites da unidade. $\mathrm{O}$ financiamento para os trabalhos de campo foi dado pelo CNPq- Edital Universal (processo no 473749/2008-4). Agradecemos ao Instituto Chico Mendes pela autorização para atividades com finalidade científica $\left(\mathrm{n}^{\mathrm{o}}\right.$ 20096-1). 
Ab'Sáber, A. \& Bernardes, N. 1958. Vale do Paraíba, Serra da Mantiqueira e arredores de São Paulo. In: Congresso Internacional de Geografia XVIII: guia de excursões (4). Conselho Nacional de Geografia, Rio de Janeiro.

Amorim, H.B. (coord.) 1984. Inventário Florestal Nacional: florestas nativas - Rio de Janeiro e Espírito Santo. Instituto Brasileiro de Desenvolvimento Florestal - IBDF, Brasília.

Anchieta, J. 1560. Carta ao Padre Geral de São Vicente ao ultimo de Maio de 1560. In: J.P.O. Costa (ed.), 1997, Carta de São Vicente 1560. Série Cadernos da Reserva da Biosfera da Mata Atlântica no. 7. Conselho Nacional da Reserva da Biosfera da Mata Atlântica, Secretaria de Estado do Meio Ambiente do Estado de São Paulo e Instituto Florestal do Estado de São Paulo, São Paulo.

Attayde, J.L.; Okun, N; Brasil, J.; Menezes, R. \& Mesquita, P. 2007. Impactos da introdução da tilápia do Nilo, Oreochromis niloticus, sobre a estrutura trófica dos ecossistemas aquáticos do Bioma Caatinga. Oecologia Brasiliensis 11(3): 450-461.

Bizerril, C.R.S.F.; Araújo, L.M.N. \& Tosin, P.C. 1998. Contribuição ao Conhecimento da Bacia do Rio Paraíba do Sul: coletânea de estudos. ANEEL/CPRM, Rio de Janeiro.

Britski, H.A.; Sato, Y. \& Rosa, A.B.S. 1986. Manual de Identificação de Peixes da Região de Três Marias: com chaves de identificação para os peixes da bacia do São Francisco. 2 ed. CODEVASF. Companhia de Desenvolvimento do Vale do São Francisco, Brasília.

Buckup, P.A. 1993. Review of characidiin fishes (Teleostei: Characiformes), with descriptions of four new genera and ten new species. Ichthyological Explorations of Freshwaters 4: 97-154

Buckup, P.A.; Menezes, N.A. \& Ghazzi, M.S. (eds) 2007. Catálogo das Espécies de Peixes de Água Doce do Brasil. Série livros 23. Museu Nacional, Universidade Federal do Rio de Janeiro, Rio de Janeiro.

Burgos, D.C. 2009. Mapeamento Geomorfológico Aplicado a Análise Ambiental: estudo de caso Serra da Jaqueçaba e seu entorno (Espirito Santo - Brasil). Monografia. Universidade Federal do Espírito do Santo.

Campos da Paz, R. 1997. Sistemática e Taxonomia dos Peixes Elétricos das Bacias dos Rios Paraguai, Paraná e São Francisco, com Notas sobre Espécies Presentes em Rios Costeiros do Leste do Brasil (Teleostei: Ostariophysi: Gymnotiformes). Tese de Doutorado. Universidade de São Paulo.

Canonico, G.C.; Atherington, A.; McCrary, J.K. \& Thieme, M.L. 2005. The effects of introduced tilapias on native biodiversity. Aquatic Conservation 15: 463-483.

Carvalho Filho, A. 1999. Peixes: Costa Brasileira. Ed. Melro, São Paulo.

Castro, R.M.C. 1999. Evolução da ictiofauna de riachos sulamericanos: padrões gerais e possíveis processos causais. In: E.P. Caramaschi, R. Mazzoni, C.R.S.F. Bizerril \& P.R. PeresNeto (eds), Ecologia de Peixes de Riachos: estado atual e perspectivas. Oecologia Brasiliensis VII, Rio de Janeiro, p. $139-155$

Centofante, L.; Bertollo, L.A.C.; Buckup, P.A. \& MoreiraFilho, O. 2003. Chromosomal divergence and maintenance of sympatric Characidium fish species (Crenuchidae, Characidiinae). Hereditas 138:213-218.

CEPEMAR (Serviços de Consultoria em Meio Ambiente) 2007. Consolidação dos Encartes 1, 2, 3, 4, 5, e 6 do Plano de Manejo do Parque Estadual Paulo Cesar Vinha. Relatório Técnico CPM RT 307/07.
CNRH (Conselho Nacional de Recursos Hídricos) 2003. Resolução n ${ }^{\circ} 32,15$ de outubro de 2003. DOU-Diário Oficial da União, 17 dez. 2003.

Correia, K.V. \& Leão, B.M. 2006. O que ainda ameaça. In: M. Campanili \& M. Prochnowpp (orgs), Mata Atlântica: uma rede pela floresta. Rede de ONGs da Mata Atlântica RMA, Brasília, p. 198-234.

Dajoz, R. 1983. Ecologia Geral. 4. ed. Vozes, Petrópolis.

De Paula, A. 2006. Espírito Santo. In: M. Campanili \& M. Prochnowpp (orgs), Mata Atlântica: uma rede pela floresta. Rede de ONGs da Mata Atlântica. RMA, Brasília, p.114-128.

Dias, J.B. 2006. Impactos Sócio-econômicos e Ambientais da Introdução da Tilápia do Nilo, Oreochromis niloticus, em Açudes Públicos do Semi-árido Nordestino, Brasil. Dissertação de Mestrado. Universidade Federal do Rio Grande do Norte.

Eigenmann, C.H. 1921. The American Characidae. Memoirs of the Museum of Comparative Zoology 23(3): 209-310.

Fausto, C. 2000. Os Índios Antes do Brasil. Jorge Zahar, Rio de Janeiro.

Freire, J.R.B. \& Malheiros, M.F. 2010. Aldeamentos Indigenas do Rio de Janeiro. EDUERJ, Rio de Janeiro.

Garutti, V. 1995. Revisão Taxonômica dos Astyanax (Pisces, Characidae), com Mancha Umeral Ovalada e Mancha do Pedúnculo Caudal, Estendendo-se à Extremidade dos Raios Caudais Medianos, das Bacias do Paraná, São Francisco e Amazônica. Tese de Livre Docência. Universidade Estadual Paulista.

Garutti, V. \& Britski, H.A. 2000. Descrição de uma espécie nova de Astyanax (Teleostei: Characidae) da bacia do alto rio Paraná e considerações sobre as demais espécies do gênero na bacia. Comunicações do Museu de Ciências e Tecnologia da Pontifícia Universidade Católica do Rio Grande do Sul, Série Zoologia 13: 65-88.

Hammer, Ø.; Harper, D.A.T, \& Ryan, P.D. 2001. Past: Paleontological Statistics Software Package for Education and Data Analysis. Palaeontologia Electronica 4(1): 1-9. Disponível em http://palaeo-electronica.org/ 2001 1/past/issue1 01.htm; acesso em 13 dez. 2010.

IEMA (Instituto Estadual de Meio Ambiente e Recursos Hídricos) 2009. As Bacias Hidrográficas do Estado do Espirito Santo. Disponível em http://www.iema.es.gov.br; acesso em 20 set. 2010.

Latini, A.O. \& Petrere, M. 2004. Reduction of a native fish fauna by alien species: an example from Brazilian freshwater tropical lakes. Fisheries Management and Ecology 11: 71-79.

Lundberg, J.G.; Marshall, L.G.; Guerrero, J.; Horton, B.; Malabarba, M.C.S.L. \& Wesselingh, F. 1998. The stage for Neotropical fish diversification: a history of tropical South American rivers. In: L.R. Malabarba, R.E. Reis, R.P. Vari, Z.M.S. Lucena \& C.A.S. Lucena (eds), Phylogeny and Classification of Neotropical Fishes. Edipucrs, Porto Alegre, p. 13-48.

Magalhães, P.A.I. \& Paraíso, M.H.B. 2009. Cartas do Padre Fernão Cardim (1608-1618). Clio-Série Revista de Pesquisa Histórica 27(2): 206-246.

McCrary, J.K.; Murphy, B.R.; Stauffer Jr, J.R. \& Hendrix, S.S. 2006. Tilapia (Teleostei: Cichlidae) status in Nicaraguan natural waters. Environmental Biology of Fishes 80(1): 78-107.

Melo, F.A.G. 2005. Revisão Taxonômica do Complexo de Espécies Astyanax fasciatus (Cuvier, 1819). Tese de Doutorado. Museu Nacional. 
Menezes N.A.; Buckup, P.A.; Figueiredo, J.L. \& Moura, R.L. 2003. Catálogo das Espécies de Peixes Marinhos do Brasil. Museu de Zoologia, Universidade de São Paulo, São Paulo.

Menezes, N.A.; Weitzman, S.H.; Oyakawa O.T.; Lima, F.C.T.; Castro, R.M. \& Weitzman, M.J. 2007. Peixes de Água Doce da Mata Atlântica: lista preliminar das espécies e comentários sobre conservação de peixes de água doce neotropicais. Museu de Zoologia, Universidade de São Paulo, São Paulo.

MMA (Ministério do Meio Ambiente) 2004. Lista Nacional das Espécies de Invertebrados Aquáticos e Peixes Ameaçadas de Extinção. Instrução Normativa $n^{\circ}$ 5, 21 de Maio de 2004. In: Diário Oficial da União, seção 1, n 102 , sexta-feira, 28 de maio de 2004. Imprensa Nacional, Brasília, p. 136-141.

Moreno, C.E. 2001. Métodos para medir la biodiversidad. $M \& T$ Manuales y Tesis SEA. Vol. 1. Zaragoza, p. 84. Disponível em http://entomologia.rediris.es/sea/manytes/metodos.pdf; acesso em 15 dez. 2010.

Paiva, M.P. 2004. Rios e Peixes de Águas Interiores do Estado do Espírito Santo (Brasil). Instituto Histórico e Geográfico do Espírito Santo, Vitória.

Pereira, F.V.; Foletto, F.; Moreira, T.M.; Gomes, J.M.L. \& Bernini, E. 2009. Estrutura da vegetação em duas áreas com diferentes históricos de antropização no manguezal de Anchieta, ES. Boletim do Laboratório de Hidrobiologia 22: $1-8$.

Petri, D.J.C. 2009. Estrutura da Floresta de Mangue do Estuário do Rio Benevente, Anchieta, ES, Brasil. Monografia. Universidade Estadual do Norte Fluminense.

Pielou, E.C. 1969. Association tests versus homogeneity tests: their use in subdividing quadrats into groups. Vegetation 18: 4-18.

Pompêo, M.L.M. \& Moschini-Carlos, V. 2010. Lagoas Costeiras: Morro dos Conventos, Araranguá, litoral do extremo sul catarinense. Universidade de São Paulo. Disponível em http://ecologia.ib.usp.br/portal/index.php?option $=$ com_content $\&$ view $=$ article $\&$ id $=75 \&$ Item id=179; acesso em 23 set. 2010 .

Resende, E.K.; Marques, D.K.S. \& Ferreira, L.K.S.G. 2008. A successful case of biological invasion: the fish Cichla piquiti, an Amazonian species introduced into the Pantanal, Brazil. Brazilian Journal of Biology 68(4): 799-805.

Ribeiro, A.C. 2006. Tectonic history and the biogeography of the freshwater fishes from the coastal drainages of eastern Brazil: an example of faunal evolution associated with a divergent continental margin. Neotropical Ichthyology 4(2): 225-246.

Ruschi, A. 1965. Lista dos tubarões, raias e peixes de água doce e salgada do estado do Espírito Santo e uma observação sobre a introdução do dourado no Rio Doce. Boletim do Museu de Biologia Mello Leitão 25A: 1-24.

Santos, A.J. 2003. Estimativas de riqueza em espécies. In: L. Cullen Jr (org.), Métodos de Estudo em Biologia da Conservação e Manejo da Vida Silvestre. Ed. UFPR e Fundação O Boticário de Proteção à Natureza, Curitiba, p. $19-41$.

Sarmento-Soares, L.M. \& Martins-Pinheiro, R.F. 2009. Rios e peixes do Espírito Santo: estado atual do conhecimento da ictiofauna de água doce. Boletim SBI 95: 5-6.

Sarmento-Soares, L.M. \& Martins-Pinheiro, R.F. 2010a. A fauna de peixes da bacia dos Reis Magos e microbacias de
Serra, Espírito Santo, Brasil. Boletim do Museu de Biologia Mello Leitão, nova série 28: 105-141.

Sarmento-Soares, L.M. \& Martins-Pinheiro, R.F. 2010 b. Relação de Lotes do Espírito Santo Coletados Durante o Projeto BIOdiversES. Disponível em http://www.nossa casa.net/biodiverses/doc/anexo_a.pdf; acesso em 25 set. 2010.

Sarmento-Soares, L.M. \& Martins-Pinheiro, R.F. 2010c. Relação de Lotes do Espírito Santo Disponíveis nos Bancos de Dados Públicos das Principais Coleções Ictiólogicas do País Considerados no Projeto BIOdiversES. Disponível em http://www.nossacasa.net/biodiverses/doc/anexo_b.pdf; acesso em 25 set. 2010.

Sarmento-Soares, L.M.; Mazzoni, R. \& Martins-Pinheiro, R.F. 2008. A fauna de peixes dos rios dos Portos Seguros, extremo sul da Bahia, Brasil. Boletim do Museu de Biologia Mello Leitão, nova série 24: 119-142.

Sarmento-Soares, L.M.; Mazzoni, R. \& Martins-Pinheiro, R.F. 2009. A fauna de peixes nas bacias litorâneas da Costa do Descobrimento, extremo sul da Bahia, Brasil. Sitientibus série Ciências Biologicas 9(2/3):139-157.

SIGEL (Sistema de Informações Georreferenciadas do Setor Elétrico) 2010. Ministério de Minas e Energia. Disponível em http://sigel.aneel.gov.br/brasil; acesso em 25 set. 2010.

Silfvergrip, A.M.C. 1996. A Systematic Revision of the Neotropical Catfish Genus Rhamdia (Teleostei, Pimelodidae). Stockholm University, Stockholm.

Silva, D.S.; Pieczarka, J.C.; Milhomem, S.S.R.; Silva, P.C.; Cardoso, A.L. \& Nagamachi, C.Y. 2008. Citogenética e distribuição de Eigenmannia virescens (SternopygidaeGymnotiformes) em sistemas de rios da Amazônia Oriental. In: Resumos do $54^{\circ}$ Congresso Brasileiro de Genética, 16 a 19 de setembro de 2008, Salvador. Disponível em web2.sbg.org.br/congress/sbg2008/pdfs2008/25050.pdf; acesso em 20 set. 2010.

Travassos, H. 1955. Contribuição ao estudo da família Characidae Agassiz, 1844 - VI. Characidium alipioi n. sp. Arquivos do Museu Nacional 42: 613-619.

Vale, C.C. 2004. Séries Geomórficas Costeiras do Estado do Espírito Santo e os Habitats para o Desenvolvimento dos Manguezais: uma visão sistemica. Tese de doutorado. Universidade de São Paulo.

Vale, C.C. \& Ferreira, R.D. 1998. Os manguezais do litoral do estado do Espírito Santo. In: Anais do Simpósio de Ecossistemas da Costa Brasileira. ACIESP, São Paulo, p. 88-94.

Vervloet, R.J.H.M. 2009. Condicionantes Morfológicos e Estruturais na Dinâmica Fluvial da Bacia Hidrográfica do Rio Benevente - Espírito Santo. Dissertação de mestrado. Universidade de São Paulo.

Vieira, L.C.Z. 2007. Maricultura e turismo: possibilidades para desenvolvimento sustentável de Anchieta-ES. In: Anais do II Encontro Interdisciplinar de Ecoturismo em Unidades de Conservação, 8 de Nov. 2007, Itatiaia. Disponível em http://www.physis.org.br/ecouc/Resumos/Resumo124.pdf; acesso em 28 ago. 2010.

Vitule, J.R.S.; Freire, C.A. \& Simberloff, D. 2009. Introduction of non-native freshwater fish can certainly be bad. Fish and Fisheries 10: 1-11. 
Material das Bacias do Sudeste do Espírito Santo.

Material examinado (355 lotes). Microbacias de Guarapari: Astyanax janeiroensis MBML 3175 (10). Atherinella brasiliensis MBML 968 (32). Bryconamericus ornaticeps MBML 2327 (7). Cichla pinima MBML 962 (2). Corydoras nattereri MBML 1367 (14). Deuterodon parahybae MBML 1366 (18). Geophagus brasiliensis MBML 960 (11), MBML 1368 (2). Gymnotus pantherinus MBML 45 (1), MBML 3195 (6). Hoplias malabaricus MBML 964 (2). Hoplosternum littorale MBML 961 (2). Hypostomus affinis MBML 1370 (1). Mugil liza MBML 967 (11). Tilapia rendalli MBML 966 (21). Pimelodella pectinifer MBML 1369 (1). Poecilia vivipara MBML 965 (25), MBML 1371 (1). Prionotus punctatus MBML 114 (1), MBML 136 (2). Rhamdia sp. MBML 963 (2). Rhinobatos percellens MBML 112 (1). Trachelyopterus striatulus MBML 959 (2). Zapteryx brevirostris MBML 113 (1). Bacia do rio Benevente: Astyanax giton MBML 2535 (1), MBML 2541 (28), MBML 3316 (14), MBML 3403 (5). Astyanax intermedius MBML 1127 (2), MBML 2551 (15), MBML 2585 (28), MBML 3194 (75), MBML 3246 (92), MBML 3276 (5), MBML 3313 (7), MBML 3319 (17), MBML 3325 (1), MBML 3331 (5), MBML 3346 (12), MBML 3369 (15), MBML 3392 (3), MBML 3393 (9), MBML 3395 (2), MBML 3413 (2). Astyanax janeiroensis MBML 1381 (31), MBML 2581 (41), MBML 3136 (206), MBML 3142 (50), MBML 3154 (157), MBML 3155 (106), MBML 3167 (5), MBML 3232 (16), MBML 3233 (130), MBML 3245 (134), MBML 3264 (110), MBML 3407 (1). Astyanax sp. 1 aff. A. lacustris MBML 1380 (16), MBML 2542 (1), MBML 3164 (3), MBML 3240 (4), MBML 3254 (2), MBML 3266 (1), MBML 3275 (2), MBML 3305 (2), MBML 3310 (4), MBML 3315 (5), MBML 3348 (2), MBML 3355 (3), MBML 3371 (1), MBML 3402 (2). Bryconamericus ornaticeps MBML 571 (13), MBML 3229 (63). Australoheros muriae MBML 2830 (1). Awaous tajasica MBML 2545 (1), MBML 2574 (2), MBML 3190 (1), MBML 3320 (1), MBML 3332 (1). Callichthys callichthys MBML 3404 (4). Characidium sp. 1 aff. $C$. alipioi MBML 505 (9), MBML 551 (9), MBML 1123 (23), MBML 1379 (23), MBML 2582 (1), MBML 2691 (1), MBML 3139 (6), MBML 3188 (3), MBML 3224 (2), MBML 3399 (1), MBML 3406 (2), Cichla pinima MBML 3340 (1). Corydoras nattereri MBML 1121 (51), MBML 1433 (226), MBML 3057 (5), MBML 3114 (29), MBML 3128 (38), MBML 3133 (39), MBML 3153 (23), MBML 3191 (22), MBML 3200 (2), MBML 3228 (42), MBML 3236 (22), MBML 3241 (16), MBML 3242 (17), MBML 3397 (1). Crenicichla lacustris MBML 506 (6), MBML 2569 (1), MBML 2572 (2), MBML 3119 (2), MBML 3179 (1), MBML 3187 (2), MBML 3221 (1), MBML 3372 (1), Cyphocharax gilbert MBML 1128 (1), MBML 2544 (1), MBML 3140 (2), MBML 3220 (2), MBML 3297 (1). Deuterodon parahybae MBML 1118 (131), MBML 2333 (5), MBML 2537 (1), MBML 2579 (11), MBML 3116 (64), MBML 3235 (90), MBML 3314 (5), MBML 3327 (4), MBML 3409 (23). Eigenmannia sp. MBML 2690 (1), MBML 3145 (3). Geophagus brasiliensis MBML 1376 (1), MBML 2543 (1), MBML 2550 (2), MBML 2576 (8), MBML 2580 (11), MBML 2584 (3), MBML 2985 (7), MBML 3111 (8), MBML 3117 (6), MBML 3129 (4), MBML 3143 (4), MBML 3171 (11), MBML 3183 (26), MBML 3227 (4), MBML 3231 (4), MBML 3268 (3), MBML 3274 (5), MBML 3312 (5), MBML 3329 (3), MBML 3333 (1), MBML 3339 (6), MBML 3347 (1), MBML 3370 (1), MBML 3394 (2), MBML 3405 (3), MBML 3410 (7), MBML 3412 (1), Glanidium melanopterum MBML 2566 (2), MBML 2571 (1). Gymnotus carapo MBML 482 (4), MBML 2577 (1), MBML 2884 (1), MBML 3150 (1), MBML 3158 (2), MBML 3160 (3), MBML 3193 (1), MBML 3323 (1), MBML 3330 (2). Gymnotus pantherinus MBML 3238 (2). Harttia loricariformis MBML 2536 (7), MBML 2575 (6). Hisonotus sp. MBML 479 (22), MBML
1120 (24), MBML 1377 (7), MBML 2681 (28), MBML 3061 (6), MBML 3120 (11), MBML 3134 (10), MBML 3135 (69), MBML 3157 (22), MBML 3159 (37), MBML 3166 (21), MBML 3169 (43), MBML 3223 (10), MBML 3259 (35), MBML 3261 (12), MBML 3269 (10), MBML 3285 (79), MBML 3398 (3), Hoplerythrinus unitaeniatus MBML 46 (1). Hoplias malabaricus MBML 1372 (3), MBML 2548 (1), MBML 2568 (1), MBML 3118 (1), MBML 3137 (1), MBML 3174 (1), MBML 3201 (3), MBML 3222 (1), MBML 3225 (1), MBML 3251 (2), MBML 3257 (2), MBML 3267 (1), MBML 3304 (4), MBML 3396 (1). Hyphessobrycon reticulatus MBML 3306 (82). Hypostomus affinis MBML 512 (2), MBML 1374 (1), MBML 2540 (1), MBML 2682 (1), MBML 3060 (1), MBML 3110 (10), MBML 3161 (5), MBML 3192 (5), MBML 3198 (5), MBML 3230 (2), MBML 3265 (5), MBML 3270 (6). Imparfinis sp. MBML 1122 (13), MBML 1375 (3), MBML 3168 (1), MBML 3272 (1), MBML 3321 (1). Leporinus copelandii MBML 480 (2), MBML 2549 (1), MBML 2573 (1). Microglanis parahybae MBML 481 (6). Oligosarcus acutirostris MBML 2546 (1), MBML 3307 (1), MBML 3311 (1). Tilapia rendalli MBML 2583 (1), MBML 3328 (2), MBML 3349 (4). Otothyris lophophanes MBML 2683 (1), MBML 3336 (17), MBML 3337 (4). Parotocinclus maculicauda MBML 573 (31), MBML 1355 (1), MBML 3185 (24), MBML 3196 (25), MBML 3322 (2), MBML 3324 (5), MBML 3334 (1). Phalloceros elachistos MBML 2538 (7), MBML 2578 (11), MBML 2586 (19), MBML 3326 (4), MBML 3335 (34), MBML 3401 (1), MBML 3408 (1). Pimelodella pectinifer MBML 572 (13), MBML 1126 (1), MBML 1378 (11), MBML 2564 (3), MBML 3113 (1), MBML 3115 (2), MBML 3177 (1), MBML 3217 (4), MBML 3234 (1), MBML 3309 (1), MBML 3317 (1). Poecilia vivipara MBML 1125 (1), MBML 2831 (7), MBML 3350 (18), MBML 3400 (2). Pomadasys ramosus MBML 2570 (1). Prochilodus vimboides MBML 478 (1), MBML 2539 (4). Rhamdia sp. MBML 2547 (1), MBML 2565 (1), MBML 2832 (1), MBML 3255 (1), MBML 3373 (1). Rineloricaria steindachneri MBML 2567 (1). Synbranchus marmoratus MBML 3263 (2). Trachelyopterus striatulus MBML 3058 (3), MBML 3126 (1), MBML 3131 (1), MBML 3204 (2). Trichomycterus caudofasciatus MBML 548 (1), MBML 1124 (2), MBML 1373 (1), MBML 3411 (5). Xiphophorus helleri MBML 3308 (2). Xiphophorus maculatus MBML 3318 (1). Bacia do Rio Novo: Astyanax intermedius MBML 2655 (4), MBML 2659 (4), MBML 2663 (2), MBML 3606 (101). Astyanax janeiroensis MBML 2813 (2), MBML 2814 (6), MBML 3031 (8). Astyanax sp. 1 aff. A. lacustris MBML 2718 (5), MBML 2730 (2), MBML 2901 (9), MBML 3027 (2), MBML 3365 (1), MBML 3366 (1). Australoheros muriae MBML 2745 (5), MBML 2817 (5), MBML 2984 (1), MBML 2986 (3), MBML 3072 (12). Caranx latus MBML 3352 (1). Centropomus parallelus MBML 3354 (1). Characidium sp. 1 aff. C. alipioi MBML 2657 (8), MBML 2662 (2). Cichla pinima MBML 3205 (2). Crenicichla lacustris MBML 2664 (1). Cyphocharax gilbert MBML 2809 (4), MBML 3122 (1). Deuterodon parahybae MBML 3358 (4), MBML 3363 (8), MBML 3367 (2), MBML 3605 (32), MBML 3609 (1). Eigenmannia sp. MBML 2819 (3), MBML 3076 (1). Eugerres brasilianus MBML 3351 (1). Geophagus brasiliensis MBML 2654 (1), MBML 2658 (2), MBML 2818 (1), MBML 3186 (7), MBML 3357 (3), MBML 3608 (6). Hisonotus sp. MBML 3362 (11). Hoplias malabaricus MBML 2811 (2). Hoplosternum littorale MBML 3353 (1). Hyphessobrycon bifasciatus MBML 2769 (15), MBML 2808 (22), MBML 2816 (13), MBML 3030 (10). Hypostomus affinis MBML 2665 (2), MBML 3356 (1). Leporinus conirostris MBML 2716 (1). Oligosarcus acutirostris MBML 2810 (4), MBML 3206 (5). Otothyris lophophanes MBML 2812 (1). Parotocinclus maculicauda MBML 3360 (3), 
MBML 3364 (1). Phalloceros elachistos MBML 3607 (3). Pimelodella pectinifer MBML 2714 (6), MBML 3130 (2), MBML 3258 (1). Poecilia reticulata MBML 2656 (7), MBML 2660 (3), MBML 3359 (11). Poecilia vivipara MBML 2719 (2), MBML 2789 (20), MBML 2815 (11), MBML 3368 (14). Rhamdia sp. MBML 2666 (1), MBML 3207 (1). Synbranchus marmoratus MBML 2720 (1). Trichomycterus caudofasciatus MBML 2661 (2), MBML 3361 (1).

Material desaparecido (14 lotes). Microbacias de Guarapari: Deuterodon parahybae CIUFES 131382 (11). Bryconamericus ornaticeps CIUFES 130663 (1). Bacia do Rio Benevente: Deuterodon parahybae CIUFES 131383 (17). Corydoras nattereri CIUFES 131578 (4). Hoplerythrinus unitaeniatus CIUFES 131571 (1). Não identificada estuarina CIUFES 131582 (4), CIUFES 131637 (2). Pimelodella pectinifer CIUFES 131237 (2), CIUFES 131239 (2). Rhamdia sp. CIUFES 130747 (3), CIUFES 131238 (2), CIUFES 131531 (1). Bacia do Rio Novo: Eucinostomus melanopterus CIUFES 130845 (6). Geophagus brasiliensis CIUFES 131128 (4).

Material consultado (196 lotes). Microbacias de Guarapari: Astyanax janeiroensis MZUSP 51782 (78). Astyanax sp. 1 aff. A. lacustris MZUSP 68981 (5). Antennarius multiocellatus ZUEC 2748 (1), ZUEC 2749 (1), ZUEC 2750 (1). Antennarius striatus ZUEC 2810 (1), ZUEC 3504 (1), ZUEC 3505 (1), ZUEC 3506 (1). Deuterodon parahybae MZUSP 51787 (114). Caranx latus CIUFES 130793 (5). Characidium sp. 1 aff. C. alipioi MZUSP 51786 (14). Citharichthys arenaceus CIUFES 130887 (5). Citharichthys spilopterus CIUFES 130888 (33), CIUFES 130928 (2). Coryphopterus glaucofraenum CIUFES 504 (1). Deuterodon parahybae MZUSP 27586 (23). Diapterus auratus CIUFES 130840 (3). Eleotris pisonis MZUSP 27589 (2). Ulaema lefroyi CIUFES 448 (7). Eucinostomus melanopterus CIUFES 130839 (9), CIUFES 130842 (17). Geophagus brasiliensis MZUSP 51780 (1). Holacanthus ciliaris CIUFES 131361 (2), ZUEC 3512 (1). Hyphessobrycon bifasciatus MZUSP 51781 (4). Lutjanus jocu CIUFES 130968 (1). Microphis brachyurus MZUSP 27588 (1). Mimagoniates microlepis MZUSP 51783 (41), MZUSP 51785 (2). Mugil curema CIUFES 131064 (2). Ogcocephalus vespertilio MBML 103 (1). Parotocinclus maculicauda MZUSP 27587 (9), MZUSP 51784 (4). Poecilia vivipara ZUEC 3309 (4). Pomadasys crocro CIUFES 131438 (2). Prionotus punctatus CIUFES 1722 (1). Sardinella brasiliensis CIUFES 454 (2). Sphoeroides greeleyi CIUFES 453 (1). Sphoeroides testudineus CIUFES 130354 (6). Stellifer rastrifer CIUFES 131718 (1). Stephanolepis hispidus CIUFES 422 (2). Stephanolepis setifer ZUEC 3511 (1). Bacia do rio Benevente: Anchovia clupeoides CIUFES 1070 (1). Astyanax giton MZUSP 21863 (3), MZUSP 21865 (3). Deuterodon parahybae MCP 29493 (14), MNRJ 23823 (1), MZUSP 21861 (6), MZUSP 21864 (1), MZUSP 21866 (3). Awaous tajasica CIUFES 68 (1), CIUFES 69 (1), CIUFES 96 (1). Bairdiella ronchus CIUFES 901 (1). Bathygobius soporator CIUFES 890 (1). Caranx hippos CIUFES 659 (1). Centropomus parallelus CIUFES 902 (1). CIUFES 1072 (1), Characidium sp. 1 aff. C. alipioi MCP 29495 (6), MNRJ 23822 (16), MNRJ 23826 (13). Ciclichthys spinosus CIUFES 399 (1). Chloroscombrus chrysurus CIUFES 1069 (1). Citharichthys arenaceus CIUFES 994 (2). Corydoras nattereri MCP 27744 (4), MCP 29496 (6), MNRJ 23821 (5). Crenicichla lacustris MCP 27723 (3). Ctenogobius boleosoma CIUFES 891 (2), CIUFES 898 (1). Ctenogobius smaragdus CIUFES 50 (2), CIUFES 52 (2), CIUFES 120 (1), CIUFES 892 (1). Ctenogobius stigmaticus CIUFES 49 (4),
CIUFES 63 (1), CIUFES 64 (1), CIUFES 305 (1), CIUFES 428 (4), CIUFES 896 (1). Deuterodon parahybae MZUSP 27590 (12). Erotelis smaragdus CIUFES 55 (1), CIUFES 56 (1), CIUFES 57 (1). Genidens genidens CIUFES 1071 (1). Gobionellus oceanicus CIUFES 1068 (1). Gobionellus stomatus CIUFES 47 (1), CIUFES 48 (18), CIUFES 65 (1), CIUFES 66 (1), CIUFES 897 (6). Gymnotus carapo MZUSP 27591 (1). Hisonotus sp. MCP 27695 (13). MCP 27702 (2), MCP 27703 (9), MCP 27708 (6), MCP 29494 (1). Hoplerythrinus unitaeniatus MZUSP 51465 (2). Hyphessobrycon reticulatus MCP 29497 (6). Hypleurochilus fissicornis CIUFES 926 (6). Hypostomus affinis MCP 29498 (1). Imparfinis sp. MCP 27729 (2), MCP 29635 (3), MNRJ 23824 (2), MZUSP 40332 (2). Lagocephalus laevigatus CIUFES 995 (1). Leporinus copelandii MCP 27733 (2). Microphis brachyurus CIUFES 131617 (1). Mugil curema CIUFES 266 (1), CIUFES 657 (1). Myrophis punctatus CIUFES 1065 (1). Não identificada estuarina CIUFES 131542 (1), CIUFES 131804 (2). Otothyris lophophanes MCP 27713 (3). Paralichthys brasiliensis CIUFES 1073 (1). Paralonchurus brasiliensis CIUFES 1067 (1). Parotocinclus maculicauda MCP 27694 (2). MCP 27698 (7), MCP 27710 (1). Peprilus paru CIUFES 983 (1). Pimelodella pectinifer MCP 29499 (1), MZUSP 40334 (2). Pomadasys crocro CIUFES 900 (1). Pomadasys ramosus CIUFES 899 (1), CIUFES 1074 (1). Pomatomus saltatrix CIUFES 1066 (1). Rhamdia sp. MZUSP 40333 (2). Rineloricaria steindachneri CIUFES 131247 (1). Scartella cristata CIUFES 927 (1). Selene vomer CIUFES 980 (1). Sphoeroides spengleri CIUFES 1064 (1). Sphoeroides testudineus CIUFES 1063 (1). Sphyraena guachancho CIUFES 903 (1). Strongylura timucu CIUFES 953 (1). Syacium papillosum CIUFES 984 (1). Bacia do Rio Novo: Aspistor luniscutis CIUFES 130025 (14). Deuterodon parahybae MCP 17762 (24). Australoheros muriae MCP 17840 (2). Bathygobius soporator CIUFES 130469 (2). Caranx latus CIUFES 130773 (7), CIUFES 130774 (8), CIUFES 130776 (1), CIUFES 130789 (3), CIUFES 130799 (3), CIUFES 130802 (8). Centropomus undecimalis CIUFES 130660 (3), CIUFES 130661 (10). Characidium sp. 1 aff. C. alipioi MNRJ 13669 (1). Citharichthys spilopterus CIUFES 130676 (3), CIUFES 130870 (2), CIUFES 130929 (1). Crenicichla lacustris MCP 18144 (6), MZUSP 54775 (3). Ctenogobius boleosoma CIUFES 130484 (1). Diapterus rhombeus CIUFES 130822 (2). Dormitator maculatus CIUFES 130520 (3), CIUFES 130522 (9), CIUFES 130534 (12). Eigenmannia sp. MCP 18107 (3), MZUSP 54781 (3). Eleotris pisonis CIUFES 130525 (1), CIUFES 130527 (7), CIUFES 130528 (1), CIUFES 130530 (1), CIUFES 130531 (2), CIUFES 130533 (1), CIUFES 130538 (3). Eucinostomus melanopterus CIUFES 130823 (4), CIUFES 130833 (3), CIUFES 130844 (9). Eugerres brasilianus CIUFES 130826 (1). Evorthodus lyricus CIUFES 130481 (1). Genidens genidens CIUFES 130021 (27), CIUFES 130028 (2). Geophagus brasiliensis MCP 18148 (6). Gobionellus oceanicus CIUFES 130460 (3). Guavina guavina CIUFES 130532 (1). Gymnotus carapo MCP 17832 (1). Hisonotus sp. MCP 18095 (12). Hoplias malabaricus MZUSP 54804 (1). Leporinus copelandii MCP 17710 (1). Lutjanus jocu CIUFES 130964 (1), CIUFES 130966 (1). Microglanis parahybae MCP 17994 (3). Microphis brachyurus CIUFES 130596 (10), CIUFES 130597 (12), CIUFES 130598 (18), CIUFES 131052 (8), CIUFES 131053 (16), MCP 18142 (3). Mugil curema CIUFES 131075 (1), Mugil trichodon CIUFES 131068 (6). Pimelodella pectinifer MCP 18004 (2). Pseudophallus mindii CIUFES 131055 (2). Synbranchus marmoratus MCP 18145 (1). Trachelyopterus striatulus CIUFES $131200(1)$. 
Apêndice 1. Comprimento dos rios e áreas das bacias, microbacias e regiões fisiográficas que configuram as bacias do sudeste do Espírito Santo.

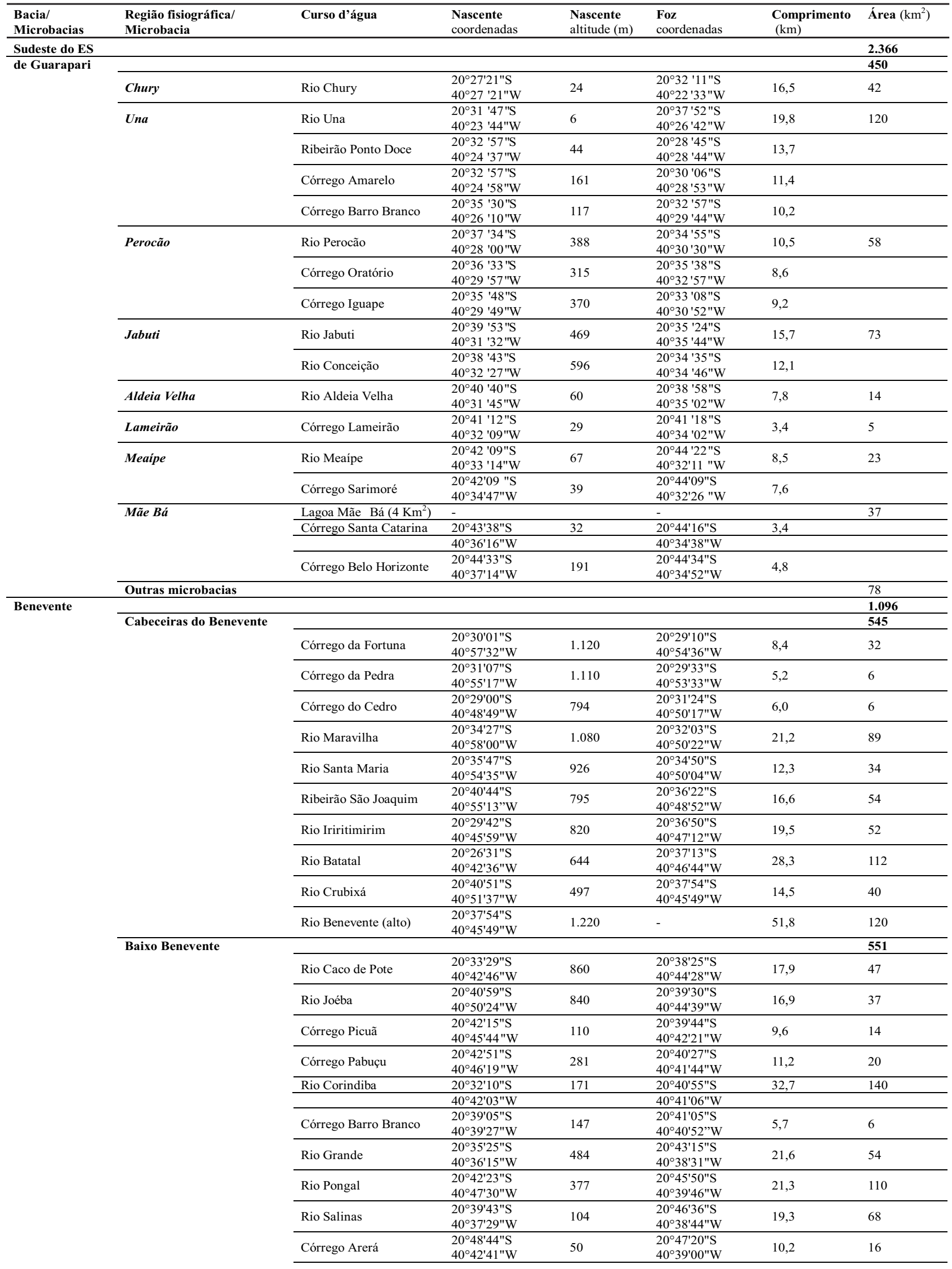




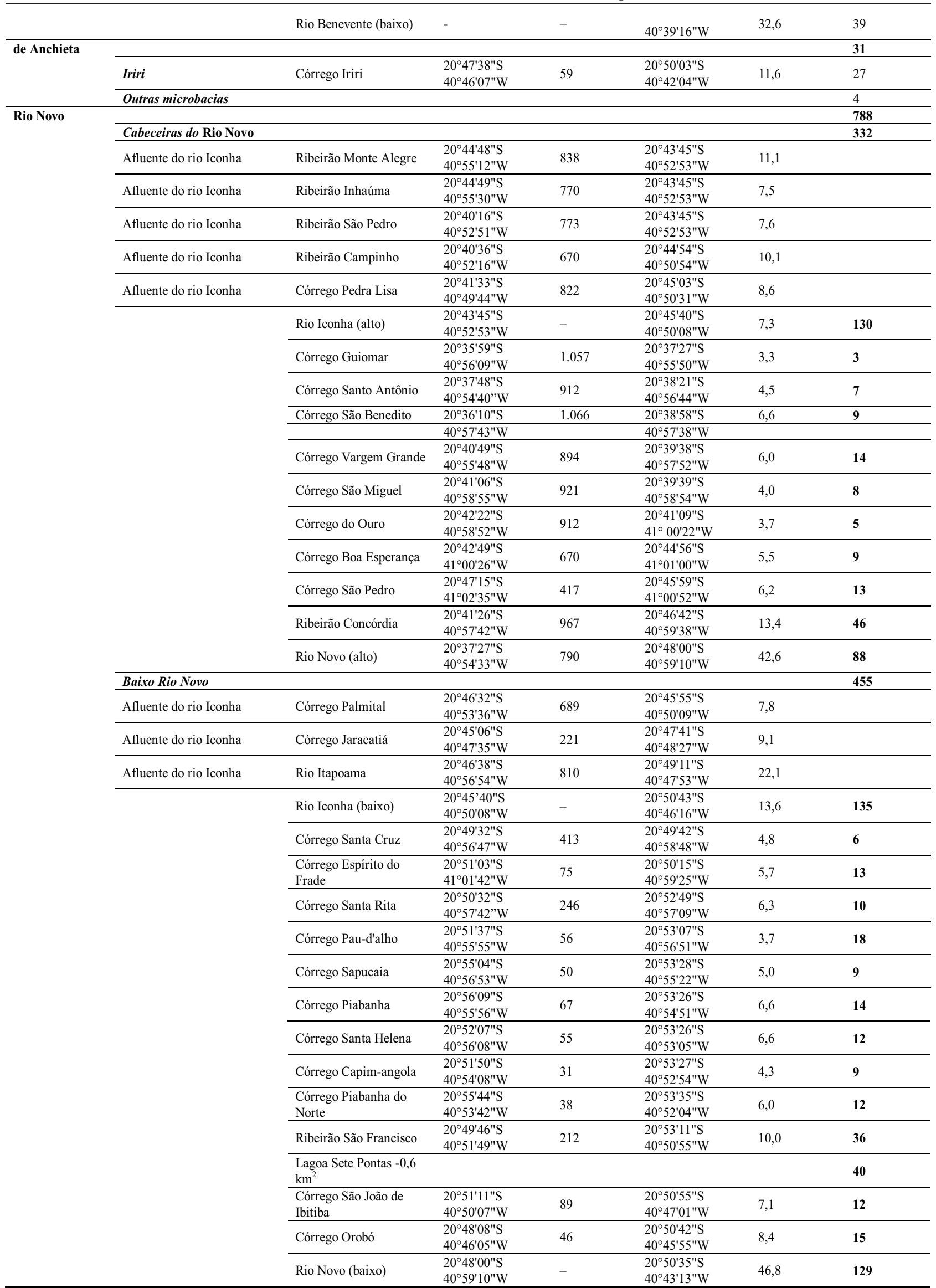


Apêndice 2. Localização geográfica, vegetação, condições da água e substrato do fundo dos pontos nas bacias do sudeste do Espírito Santo. Características da água: transparente amarelada (T1), transparente cor de chá (T2) e marrom turva (T3). Substratos: areia (Ae), argila (Ai), cascalho (C), folhiço no fundo do rio $(\mathrm{Fl})$, lodo $(\mathrm{L})$, pedra $(\mathrm{P})$ e rocha $(\mathrm{R})$.

\begin{tabular}{|c|c|c|c|c|c|c|c|c|c|c|}
\hline Pt. & Fig & $\begin{array}{l}\text { Localidade abreviada/ } \\
\text { município }\end{array}$ & Coordenadas & $\begin{array}{l}\text { Altitude } \\
\text { (m) }\end{array}$ & $\begin{array}{l}\text { Profund. } \\
\text { Amostral } \\
\text { (m) }\end{array}$ & Água & Substrato & $\begin{array}{l}\text { Vegetação } \\
\text { marginal }\end{array}$ & $\begin{array}{l}\text { Vegetação } \\
\text { aquática }\end{array}$ & $\begin{array}{l}\text { Vegetação de } \\
\text { entorno }\end{array}$ \\
\hline & & Cabeceiras do Rio Novo & & & & & & & & \\
\hline P01 & 3 & $\begin{array}{l}\text { Rio Novo próximo a } \\
\text { Jaciguá em Vargem Alta }\end{array}$ & $\begin{array}{l}20^{\circ} 42^{\prime} 31^{\prime \prime S} \\
41^{\circ} 01^{\prime} 38^{\prime \prime} \mathrm{W}\end{array}$ & 530 & $0,5-1,0$ & T1 & C-P & $\begin{array}{l}\text { Remanescentes de } \\
\text { mata ciliar }\end{array}$ & $\begin{array}{l}\text { Pouca vegetação } \\
\text { submersa }\end{array}$ & $\begin{array}{l}\text { Fragmento } \\
\text { florestal/ } \\
\text { capoeira }\end{array}$ \\
\hline P02 & 3 & $\begin{array}{l}\text { Córrego Cabral afluente do } \\
\text { Ribeirão Concórdia em } \\
\text { Vargem Alta }\end{array}$ & $\begin{array}{l}20^{\circ} 44^{\prime} 59^{\prime \prime} \mathrm{S} \\
40^{\circ} 58^{\prime} 08^{\prime \prime} \mathrm{W}\end{array}$ & 385 & $0,5-1,0$ & $\mathrm{~T} 1$ & P-R & $\begin{array}{l}\text { Remanescentes de } \\
\text { mata ciliar }\end{array}$ & $\begin{array}{l}\text { Pouca vegetação } \\
\text { submersa }\end{array}$ & $\begin{array}{l}\text { Capoeira/ } \\
\text { agricultura }\end{array}$ \\
\hline $\mathrm{P} 03$ & 3 & $\begin{array}{l}\text { Ribeirão Concórdia entre } \\
\text { confluência com Rio Cabral } \\
\text { e Rio Novo em Rio Novo do } \\
\text { Sul }\end{array}$ & $\begin{array}{l}20^{\circ} 46^{\prime} 02^{\prime \prime} \mathrm{S} \\
40^{\circ} 58^{\prime} 44^{\prime \prime} \mathrm{W}\end{array}$ & 350 & $0,5-1,0$ & $\mathrm{~T} 1$ & P-R & $\begin{array}{l}\text { Abundantes } \\
\text { gramíneas }\end{array}$ & $\begin{array}{l}\text { Pouca vegetação } \\
\text { submersa }\end{array}$ & $\begin{array}{l}\text { Capoeira/ } \\
\text { fragmento } \\
\text { florestal }\end{array}$ \\
\hline P04 & 3 & $\begin{array}{l}\text { Rio Novo à jusante da foz } \\
\text { do Ribeirão Concórdia em } \\
\text { Rio Novo do Sul }\end{array}$ & $\begin{array}{l}20^{\circ} 47^{\prime} 25^{\prime \prime} \mathrm{S} \\
40^{\circ} 59^{\prime} 32^{\prime \prime} \mathrm{W}\end{array}$ & 70 & $0,5-1,0$ & $\mathrm{~T} 1$ & P-R & $\begin{array}{l}\text { Abundantes } \\
\text { gramíneas }\end{array}$ & $\begin{array}{l}\text { Pouca vegetação } \\
\text { submersa }\end{array}$ & $\begin{array}{l}\text { Capoeira/ } \\
\text { fragmento } \\
\text { florestal }\end{array}$ \\
\hline \multirow[t]{2}{*}{$\mathrm{P} 05$} & 3 & $\begin{array}{l}\text { Ribeirão Monte Alegre sob } \\
\text { ES-375, na divisa em } \\
\text { Iconha na divisa com Rio } \\
\text { Novo do Sul }\end{array}$ & $\begin{array}{l}20^{\circ} 42^{\prime} 34^{\prime \prime} \mathrm{S} \\
40^{\circ} 55^{\prime} 07^{\prime \prime} \mathrm{W}\end{array}$ & 370 & $0,3-0,6$ & $\mathrm{~T} 1$ & C-P & Poucas gramíneas & Ausente & $\begin{array}{l}\text { Pasto/ } \\
\text { agricultura }\end{array}$ \\
\hline & & Baixo Rio Novo & & & & & & & & \\
\hline P06 & 3 & $\begin{array}{l}\text { Rio Novo do Sul, na BR } \\
101 \text { em Rio Novo do Sul na } \\
\text { divisa com Itapemirim }\end{array}$ & $\begin{array}{l}20^{\circ} 52^{\prime} 31^{\prime \prime S} \\
40^{\circ} 57^{\prime} 46^{\prime \prime} \mathrm{W}\end{array}$ & 7 & $0,5-1,0$ & $\mathrm{~T} 1$ & C-P & $\begin{array}{l}\text { Moderadas } \\
\text { gramíneas }\end{array}$ & $\begin{array}{l}\text { pouca vegetação } \\
\text { submersa }\end{array}$ & $\begin{array}{l}\text { Pasto/ } \\
\text { agricultura }\end{array}$ \\
\hline P07 & 3 & $\begin{array}{l}\text { Córrego São Vicente de } \\
\text { Baixo, afluente do Córrego } \\
\text { Pau-d'alho em Rio Novo do } \\
\text { Sul }\end{array}$ & $\begin{array}{l}20^{\circ} 51^{\prime} 18^{\prime \prime} \mathrm{S} \\
40^{\circ} 55^{\prime} 59^{\prime \prime} \mathrm{W}\end{array}$ & 75 & $1,0-1,5$ & $\mathrm{~T} 3$ & Ae-C & $\begin{array}{l}\text { Mata ciliar e } \\
\text { capoeira }\end{array}$ & $\begin{array}{l}\text { Abundantes } \\
\text { macrófitas e } \\
\text { vegetação } \\
\text { submersa. }\end{array}$ & $\begin{array}{l}\text { Mata } \\
\text { secundária/ } \\
\text { capoeira }\end{array}$ \\
\hline P08 & 3 & $\begin{array}{l}\text { Rio Iconha próximo a sede } \\
\text { do município de Iconha }\end{array}$ & $\begin{array}{l}20^{\circ} 46^{\prime} 36^{\prime \prime} \mathrm{S} \\
40^{\circ} 48^{\prime} 42^{\prime \prime} \mathrm{W}\end{array}$ & 35 & $0,3-0,6$ & $\mathrm{~T} 1$ & Ae-Ai & $\begin{array}{l}\text { Abundantes } \\
\text { gramíneas }\end{array}$ & $\begin{array}{l}\text { pouca vegetação } \\
\text { submersa }\end{array}$ & $\begin{array}{l}\text { Agricultura/ } \\
\text { habitação }\end{array}$ \\
\hline P09 & 3 & $\begin{array}{l}\text { Afluente do Ribeirão São } \\
\text { Francisco/ Rio Novo do Sul }\end{array}$ & $\begin{array}{l}20^{\circ} 51^{\prime} 14^{\prime \prime} \mathrm{S} \\
40^{\circ} 52^{\prime} 06^{\prime \prime} \mathrm{W}\end{array}$ & 45 & $0,5-1,0$ & T1 & $\mathrm{Ae}-\mathrm{Ai}$ & $\begin{array}{l}\text { Abundantes } \\
\text { gramíneas }\end{array}$ & $\begin{array}{l}\text { pouca vegetação } \\
\text { emergente }\end{array}$ & Pasto \\
\hline P10 & 3 & $\begin{array}{l}\text { Lagoa Guanandy ou Lagoa } \\
\text { Sete Pontas em Itapemirim }\end{array}$ & $\begin{array}{l}20^{\circ} 55^{\prime} 57^{\prime \prime} \mathrm{S} \\
40^{\circ} 49^{\prime} 27^{\prime \prime} \mathrm{W}\end{array}$ & 10 & $1,0-1,5$ & T2 & $\mathrm{Ae}$ & Mata de restinga & $\begin{array}{l}\text { Abundantes } \\
\text { macrófitas, taboas e } \\
\text { vegetação } \\
\text { emergente. } \\
\end{array}$ & Restinga \\
\hline P11 & 3 & $\begin{array}{l}\text { Rio Novo antes da foz do } \\
\text { rio Iconha em Piúma }\end{array}$ & $\begin{array}{l}20^{\circ} 51^{\prime 2} 26^{\prime \prime S} \\
40^{\circ} 47^{\prime} 27^{\prime \prime} \mathrm{W}\end{array}$ & 10 & $1,0-1,5$ & T1 & $\mathrm{Ae}-\mathrm{Ai}$ & $\begin{array}{l}\text { Mata de restinga e } \\
\text { gramíneas }\end{array}$ & $\begin{array}{l}\text { Pouca vegetação } \\
\text { emergente }\end{array}$ & $\begin{array}{l}\text { Restinga/ } \\
\text { agricultura }\end{array}$ \\
\hline $\mathrm{P} 12$ & 3 & $\begin{array}{l}\text { Rio Iconha na foz do rio } \\
\text { Novo em Piúma }\end{array}$ & $\begin{array}{l}20^{\circ} 50^{\prime} 39^{\prime \prime} \mathrm{S} \\
40^{\circ} 46^{\prime} 14 " \mathrm{~W}\end{array}$ & 5 & $1,5-2,0$ & $\mathrm{~T} 3$ & $\mathrm{Ae}$ & Manguezal & $\begin{array}{l}\text { Moderada } \\
\text { vegetação } \\
\text { emergente }\end{array}$ & $\begin{array}{l}\text { Restinga/ } \\
\text { habitação }\end{array}$ \\
\hline \multirow[t]{2}{*}{ P13 } & RN0103 & $\begin{array}{l}\text { Rio Novo próximo a Monte } \\
\text { Aghá em Piúma }\end{array}$ & $\begin{array}{l}20^{\circ} 51^{\prime} 05^{\prime \prime} \mathrm{S} \\
40^{\circ} 45^{\prime} 25^{\prime \prime} \mathrm{W}\end{array}$ & 0 & $1,5-2,0$ & T1 & $\mathrm{Ae}$ & $\begin{array}{l}\text { Manguezal e } \\
\text { gramíneas }\end{array}$ & $\begin{array}{l}\text { Moderada } \\
\text { vegetação } \\
\text { emergente }\end{array}$ & $\begin{array}{l}\text { Capoeira/ } \\
\text { habitação }\end{array}$ \\
\hline & & $\begin{array}{l}\text { Cabeceiras do Rio } \\
\text { Benevente }\end{array}$ & & & & & & & & \\
\hline P14 & 3 & $\begin{array}{l}\text { Rio Benevente em São } \\
\text { Bento de Urânia/ Alfredo } \\
\text { Chaves }\end{array}$ & $\begin{array}{l}20^{\circ} 28^{\prime} 31^{\prime \prime S} \\
40^{\circ} 54^{\prime} 53^{\prime \prime} \mathrm{W}\end{array}$ & 990 & $0,5-1,0$ & T1 & C-P-Fl & Mata ciliar & $\begin{array}{l}\text { Moderada } \\
\text { vegetação submersa }\end{array}$ & $\begin{array}{l}\text { Mata ciliar/ } \\
\text { capoeira }\end{array}$ \\
\hline P15 & 3 & $\begin{array}{l}\text { Rio Benevente em Matilde } \\
\mathrm{em} \text { Alfredo Chaves }\end{array}$ & $\begin{array}{l}20^{\circ} 33^{\prime} 18^{\prime \prime} \mathrm{S} \\
40^{\circ} 48^{\prime} 53^{\prime \prime} \mathrm{W}\end{array}$ & 515 & $0,5-1,0$ & T1 & P-R & Poucas gramíneas & $\begin{array}{l}\text { Moderada } \\
\text { vegetação submersa }\end{array}$ & $\begin{array}{l}\text { Capoeira/ } \\
\text { agricultura }\end{array}$ \\
\hline P16 & 3 & $\begin{array}{l}\text { Ribeirão São Joaquim em } \\
\text { Alfredo Chaves }\end{array}$ & $\begin{array}{l}20^{\circ} 36^{\prime} 54^{\prime \prime} \mathrm{S} \\
40^{\circ} 49^{\prime} 24^{\prime \prime} \mathrm{W}\end{array}$ & 406 & $0,5-1,0$ & T1 & P-R & $\begin{array}{l}\text { Moderadas } \\
\text { gramíneas }\end{array}$ & $\begin{array}{l}\text { Pouca vegetação } \\
\text { submersa }\end{array}$ & $\begin{array}{l}\text { Capoeira/ } \\
\text { agricultura }\end{array}$ \\
\hline P17 & - & $\begin{array}{l}\text { Rio Benevente a jusante da } \\
\text { barragem da PCH São } \\
\text { Joaquim em Alfredo } \\
\text { Chaves }\end{array}$ & $\begin{array}{l}20^{\circ} 36^{\prime} 14^{\prime \prime} \mathrm{S} \\
40^{\circ} 48^{\prime} 18^{\prime \prime} \mathrm{W}\end{array}$ & 290 & $1,0-1,5$ & T3 & C-P-Fl & Mata ciliar & $\begin{array}{l}\text { Moderada } \\
\text { vegetação submersa }\end{array}$ & $\begin{array}{l}\text { Mata ciliar/ } \\
\text { capoeira }\end{array}$ \\
\hline P18 & 3 & $\begin{array}{l}\text { Rio Iriritimirim em } \\
\text { Alfredo Chaves }\end{array}$ & $\begin{array}{l}20^{\circ} 32^{\prime} 27^{\prime \prime} \mathrm{S} \\
40^{\circ} 47^{\prime} 17^{\prime \prime} \mathrm{W}\end{array}$ & 530 & $1,0-1,5$ & T3 & $\mathrm{Ae}-\mathrm{Ai}$ & $\begin{array}{l}\text { Moderadas } \\
\text { gramíneas }\end{array}$ & $\begin{array}{l}\text { Pouca vegetação } \\
\text { flutuante }\end{array}$ & $\begin{array}{l}\text { Capoeira/ } \\
\text { fragmento } \\
\text { florestal }\end{array}$ \\
\hline P19 & 4 & $\begin{array}{l}\text { Afluente do Rio Batatal em } \\
\text { São Bento do Batatal em } \\
\text { Alfredo Chaves }\end{array}$ & $\begin{array}{l}20^{\circ} 30^{\prime} 39^{\prime \prime} \mathrm{S} \\
40^{\circ} 42^{\prime} 32^{\prime \prime} \mathrm{W}\end{array}$ & 560 & $1,0-1,5$ & $\mathrm{~T} 3$ & $\mathrm{Ae}-\mathrm{Ai}$ & Poucas gramíneas & $\begin{array}{l}\text { Pouca vegetação } \\
\text { flutuante }\end{array}$ & Capoeira \\
\hline \multirow[t]{2}{*}{ P20 } & 4 & $\begin{array}{l}\text { Rio Batatal em São } \\
\text { Francisco do Batatal em }\end{array}$ & $\begin{array}{l}20^{\circ} 32^{\prime} 55^{\prime \prime} \mathrm{S} \\
40^{\circ} 43^{\prime} 31^{\prime \prime} \mathrm{W}\end{array}$ & 272 & $0,5-1,0$ & $\mathrm{~T} 1$ & P-R-C-Fl & Mata ciliar & $\begin{array}{l}\text { Pouca vegetação } \\
\text { submersa }\end{array}$ & Mata ciliar \\
\hline & & Alfredo Chaves & & & & & & & & \\
\hline P21 & - & $\begin{array}{l}\text { Córrego Gavião, tributário } \\
\text { do Rio Crubixá em Alfredo } \\
\text { Chaves }\end{array}$ & $\begin{array}{l}20^{\circ} 39^{\prime} 16^{\prime \prime} \mathrm{S} \\
40^{\circ} 47^{\prime} 22^{\prime \prime} \mathrm{W}\end{array}$ & 350 & $1,0-1,5$ & $\mathrm{~T} 3$ & Ae-Ai-R & Poucas gramíneas & $\begin{array}{l}\text { Pouca vegetação } \\
\text { submersa }\end{array}$ & $\begin{array}{l}\text { Capoeira/ mata } \\
\text { secundária }\end{array}$ \\
\hline
\end{tabular}


L. M. Sarmento-Soares et al. - Peixes do Sudeste do Espírito Santo

\begin{tabular}{|c|c|c|c|c|c|c|c|c|c|c|}
\hline \multirow[b]{2}{*}{$\mathrm{P} 22$} & \multirow[b]{2}{*}{4} & \multicolumn{9}{|l|}{ Baixo Rio Benevente } \\
\hline & & $\begin{array}{l}\text { Rio Caco do Pote perto do } \\
\text { povoado Caco do Pote em } \\
\text { Alfredo Chaves }\end{array}$ & $\begin{array}{l}20^{\circ} 36^{\prime} 30^{\prime \prime} \mathrm{S} \\
40^{\circ} 43^{\prime} 16^{\prime \prime} \mathrm{W}\end{array}$ & 18 & $1,0-1,5$ & $\mathrm{~T} 1$ & P-R-C-Fl & $\begin{array}{l}\text { Remanescentes de } \\
\text { mata ciliar }\end{array}$ & $\begin{array}{l}\text { Moderada } \\
\text { vegetação submersa }\end{array}$ & $\begin{array}{l}\text { Capoeira/ mata } \\
\text { secundária }\end{array}$ \\
\hline $\mathrm{P} 23$ & - & $\begin{array}{l}\text { Rio Benevente a jusante de } \\
\text { Alfredo Chaves em Alfredo } \\
\text { Chaves }\end{array}$ & $\begin{array}{l}20^{\circ} 39^{\prime} 05^{\prime \prime S} \\
40^{\circ} 44^{\prime} 59^{\prime \prime} \mathrm{W}\end{array}$ & 11 & $1,0-1,5$ & T3 & $\mathrm{Ae}-\mathrm{Ai}$ & $\begin{array}{l}\text { Moderadas } \\
\text { gramíneas }\end{array}$ & $\begin{array}{l}\text { Pouca vegetação } \\
\text { flutuante }\end{array}$ & Pasto/ capoeira \\
\hline P24 & - & Rio Joeba em Anchieta & $\begin{array}{l}20^{\circ} 41^{\prime} 35^{\prime \prime} \mathrm{S} \\
40^{\circ} 46^{\prime} 10^{\prime \prime} \mathrm{W} \\
\end{array}$ & 18 & $1,0-1,5$ & T3 & Ae-Ai & Poucas gramíneas & $\begin{array}{l}\text { Pouca vegetação } \\
\text { submersa }\end{array}$ & Pasto/ capoeira \\
\hline $\mathrm{P} 25$ & 4 & $\begin{array}{l}\text { Córrego Cachoeira Alta } \\
\text { afluente do Rio Joéba em } \\
\text { Alfredo Chaves }\end{array}$ & $\begin{array}{l}20^{\circ} 40^{\prime} 27^{\prime \prime S} \\
40^{\circ} 47^{\prime} 11^{\prime \prime} \mathrm{W}\end{array}$ & 370 & $0,5-1,0$ & $\mathrm{~T} 3$ & $\mathrm{P}-\mathrm{Ai}$ & $\begin{array}{l}\text { Moderadas } \\
\text { gramíneas }\end{array}$ & $\begin{array}{l}\text { Pouca vegetação } \\
\text { submersa }\end{array}$ & Capoeira \\
\hline P26 & - & $\begin{array}{l}\text { Rio Joeba sob ES-164 em } \\
\text { Alfredo Chaves }\end{array}$ & $\begin{array}{l}20^{\circ} 39^{\prime} 30^{\prime \prime} \mathrm{S} \\
40^{\circ} 44^{\prime} 52^{\prime \prime} \mathrm{W}\end{array}$ & 14 & $1,0-1,5$ & T3 & $\mathrm{Ae}-\mathrm{Ai}$ & $\begin{array}{l}\text { Moderadas } \\
\text { gramíneas }\end{array}$ & $\begin{array}{l}\text { Moderada } \\
\text { vegetação submersa }\end{array}$ & Pasto/ capoeira \\
\hline P27 & 4 & $\begin{array}{l}\text { Córrego São Miguel, } \\
\text { tributário do Rio Corindiba }\end{array}$ & $\begin{array}{l}20^{\circ} 34^{\prime} 42^{\prime \prime S} \\
40^{\circ} 36^{\prime} 48^{\prime \prime} \mathrm{W}\end{array}$ & 360 & $0,5-1,0$ & $\mathrm{~T} 1$ & Ae-Ai & $\begin{array}{l}\text { Remanescentes de } \\
\text { mata ciliar }\end{array}$ & $\begin{array}{l}\text { Moderada } \\
\text { vegetação submersa } \\
\text { e flutuante }\end{array}$ & $\begin{array}{l}\text { Capoeira/ mata } \\
\text { secundária }\end{array}$ \\
\hline P28 & - & $\begin{array}{l}\text { Córrego Venuto afluente do } \\
\text { Rio Corindiba à montante } \\
\text { da rodovia BR-101 em } \\
\text { Anchieta }\end{array}$ & $\begin{array}{l}20^{\circ} 38^{\prime} 32^{\prime \prime} \mathrm{S} \\
40^{\circ} 42^{\prime} 18^{\prime \prime} \mathrm{W}\end{array}$ & 18 & $1,0-1,5$ & $\mathrm{~T} 1$ & $\mathrm{Ae}-\mathrm{Ai}$ & $\begin{array}{l}\text { Moderadas } \\
\text { gramíneas }\end{array}$ & $\begin{array}{l}\text { Moderada } \\
\text { vegetação submersa }\end{array}$ & $\begin{array}{l}\text { Capoeira/ } \\
\text { agricultura }\end{array}$ \\
\hline P29 & 4 & $\begin{array}{l}\text { Rio Benevente próximo ao } \\
\text { povoado de Jabaquara em } \\
\text { Anchieta }\end{array}$ & $\begin{array}{l}20^{\circ} 41^{\prime} 08^{\prime \prime} \mathrm{S} \\
40^{\circ} 40^{\prime} 44^{\prime \prime} \mathrm{W}\end{array}$ & 8 & $1,5-2,0$ & $\mathrm{~T} 3$ & Ae-Ai & $\begin{array}{l}\text { Remanescentes de } \\
\text { mata ciliar }\end{array}$ & $\begin{array}{l}\text { Abundante } \\
\text { vegetação } \\
\text { emergente }\end{array}$ & Capoeira/ mata \\
\hline P30 & 4 & $\begin{array}{l}\text { Rio Grande, próximo a } \\
\text { Jaqueira em Guarapari na } \\
\text { divisa com Anchieta }\end{array}$ & $\begin{array}{l}20^{\circ} 38^{\prime} 44^{\prime \prime S} \\
40^{\circ} 37^{\prime} 43^{\prime \prime} \mathrm{W}\end{array}$ & 18 & $0,5-1,0$ & T3 & Ae-Ai & Poucas gramíneas & $\begin{array}{l}\text { Pouca vegetação } \\
\text { emergente }\end{array}$ & $\begin{array}{l}\text { Capoeira/ } \\
\text { pasto }\end{array}$ \\
\hline P31 & 4 & $\begin{array}{l}\text { Rio Grande, próximo a } \\
\text { Jaqueira em Anchieta na } \\
\text { divisa com Guarapari } \\
\end{array}$ & $\begin{array}{l}20^{\circ} 39^{\prime} 46^{\prime \prime S} \\
40^{\circ} 38^{\prime} 43^{\prime \prime} \mathrm{W}\end{array}$ & 15 & $0,5-1,0$ & T3 & $\mathrm{Ae}-\mathrm{Ai}$ & poucas gramíneas & $\begin{array}{l}\text { Pouca vegetação } \\
\text { emergente }\end{array}$ & $\begin{array}{l}\text { Capoeira/ } \\
\text { pasto }\end{array}$ \\
\hline P32 & 4 & Rio Grande em Anchieta & $\begin{array}{l}20^{\circ} 41^{\prime} 56^{\prime \prime} \mathrm{S} \\
40^{\circ} 40^{\prime} 00^{\prime \prime} \mathrm{W}\end{array}$ & 8 & $1,0-1,5$ & $\mathrm{~T} 3$ & Ae-C-P & $\begin{array}{l}\text { Abundantes } \\
\text { gramíneas }\end{array}$ & $\begin{array}{l}\text { Pouca vegetação } \\
\text { submersa }\end{array}$ & Capoeira \\
\hline P33 & 4 & Rio Pongal próximo a Alto & $20^{\circ} 44^{\prime} 50^{\prime \prime} \mathrm{S}$ & 10 & 1,0 & T3 & $\mathrm{Ae}-\mathrm{C}$ & moderadas & Pouca vegetação & Capoeira/ \\
\hline & & Pongal em Anchieta & $40^{\circ} 45^{\prime} 37^{\prime \prime} \mathrm{W}$ & & & & & gramíneas & emergente & pasto \\
\hline P34 & 4 & $\begin{array}{l}\text { Córrego Taquara do Reino } \\
\text { em Guarapari }\end{array}$ & $\begin{array}{l}20^{\circ} 42^{\prime} 29^{\prime \prime} \mathrm{S} \\
40^{\circ} 35^{\prime} 30^{\prime \prime} \mathrm{W}\end{array}$ & 30 & 1,0 & $\mathrm{~T} 2$ & Ae-L & $\begin{array}{l}\text { Abundantes } \\
\text { samambaias }\end{array}$ & $\begin{array}{l}\text { Abundantes } \\
\text { macrófitas, taboas e } \\
\text { vegetação } \\
\text { emergente. }\end{array}$ & $\begin{array}{l}\text { Restinga/ mata } \\
\text { secundária }\end{array}$ \\
\hline P35 & 4 & Rio Salinas em Anchieta & $\begin{array}{l}20^{\circ} 42^{\prime} 49^{\prime \prime S} \\
40^{\circ} 38^{\prime} 08^{\prime \prime} \mathrm{W}\end{array}$ & 1 & 1,0 & $\mathrm{~T} 2$ & Ae- L & $\begin{array}{l}\text { Moderadas } \\
\text { gramíneas }\end{array}$ & $\begin{array}{l}\text { Abundantes taboas } \\
\text { e vegetação } \\
\text { emergente. }\end{array}$ & \\
\hline P36 & 4 & $\begin{array}{l}\text { Estuário do rio Benevente } \\
\text { em Anchieta }\end{array}$ & $\begin{array}{l}20^{\circ} 48^{\prime} 19^{\prime \prime} \mathrm{S} \\
40^{\circ} 39^{\prime} 16^{\prime \prime} \mathrm{W}\end{array}$ & 0 & $1,5-2,0$ & $\mathrm{~T} 2$ & Ae-L & Manguezal & $\begin{array}{l}\text { Abundante } \\
\text { vegetação } \\
\text { emergente }\end{array}$ & Manguezal \\
\hline & & $\begin{array}{l}\text { Microbacias de } \\
\text { Guarapari }\end{array}$ & & & & & & & & \\
\hline P37 & 4 & $\begin{array}{l}\text { Lagoa Mãe Bá em } \\
\text { Anchieta }\end{array}$ & $\begin{array}{l}20^{\circ} 45^{\prime} 22^{\prime \prime} \mathrm{S} \\
40^{\circ} 34^{\prime} 12^{\prime \prime} \mathrm{W}\end{array}$ & 0 & $1,5-2,0$ & $\mathrm{~T} 2$ & Ae- L & $\begin{array}{l}\text { Abundantes } \\
\text { macrófitas e } \\
\text { samambaias }\end{array}$ & $\begin{array}{l}\text { Abundantes } \\
\text { macrófitas taboas e } \\
\text { vegetação } \\
\text { emergente. }\end{array}$ & $\begin{array}{l}\text { Restinga/ } \\
\text { habitação }\end{array}$ \\
\hline P38 & 4 & $\begin{array}{l}\text { Baía de Guarapari em } \\
\text { Guarapari }\end{array}$ & $\begin{array}{l}20^{\circ} 40^{\prime} 13 ” \mathrm{~S} \\
40^{\circ} 31^{\prime} 42^{\prime \prime} \mathrm{W}\end{array}$ & 0 & $1,0-1,5$ & T3 & Ae- $C-\mathrm{L}$ & Manguezal & $\begin{array}{l}\text { Moderada } \\
\text { vegetação } \\
\text { emergente e } \\
\text { flutuante } \\
\end{array}$ & $\begin{array}{l}\text { Manguezal/ } \\
\text { habitação }\end{array}$ \\
\hline P39 & 4 & $\begin{array}{l}\text { Rio Jaboti, trecho médio } \\
\text { Guarapari }\end{array}$ & $\begin{array}{l}20^{\circ} 37^{\prime} 53 ” \mathrm{~S} \\
40^{\circ} 35^{\prime} 16^{\prime \prime} \mathrm{W}\end{array}$ & 30 & 1,0 & T3 & $\mathrm{Ae}-\mathrm{Ai}$ & $\begin{array}{l}\text { Moderadas } \\
\text { gramíneas }\end{array}$ & $\begin{array}{l}\text { Abundante } \\
\text { vegetação } \\
\text { emergente }\end{array}$ & $\begin{array}{l}\text { Mata } \\
\text { secundária/ } \\
\text { agricultura }\end{array}$ \\
\hline P40 & 4 & $\begin{array}{l}\text { Rio Conceição sob a BR- } \\
101 \text { em Guarapari }\end{array}$ & $\begin{array}{l}20^{\circ} 38^{\prime} 11^{\prime \prime S} \\
40^{\circ} 32^{\prime} 34^{\prime \prime} \mathrm{W}\end{array}$ & 30 & $0,3-0,5$ & $\mathrm{~T} 2$ & $\mathrm{Ae}-\mathrm{Ai}$ & $\begin{array}{l}\text { Abundantes } \\
\text { gramíneas e plantas } \\
\text { emergentes }\end{array}$ & $\begin{array}{l}\text { Abundante } \\
\text { vegetação flutuante }\end{array}$ & Capoeira \\
\hline P41 & 4 & $\begin{array}{l}\text { Rio Iguape (Rio Banqueta) } \\
\text { em Guarapari }\end{array}$ & $\begin{array}{l}20^{\circ} 33 ' 50 ” \mathrm{~S} \\
40^{\circ} 29^{\prime} 49^{\prime \prime} \mathrm{W}\end{array}$ & 50 & 1,0 & $\mathrm{~T} 2$ & $\mathrm{Ae}-\mathrm{Ai}$ & $\begin{array}{l}\text { Abundantes } \\
\text { macrófitas e } \\
\text { samambaias }\end{array}$ & $\begin{array}{l}\text { Abundantes } \\
\text { macrófitas taboas e } \\
\text { vegetação } \\
\text { emergente. }\end{array}$ & $\begin{array}{l}\text { Mata } \\
\text { secundária/ } \\
\text { agricultura }\end{array}$ \\
\hline P42 & 4 & $\begin{array}{l}\text { Barra do rio Perocão em } \\
\text { Guarapari }\end{array}$ & $\begin{array}{l}20^{\circ} 37^{\prime} 33^{\prime \prime} \mathrm{S} \\
40^{\circ} 27^{\prime} 58^{\prime \prime} \mathrm{W}\end{array}$ & 0 & $1,5-2,0$ & T3 & Ai- L & $\begin{array}{l}\text { Manguezal e } \\
\text { plantas emergentes }\end{array}$ & $\begin{array}{l}\text { Abundante } \\
\text { vegetação } \\
\text { emergente }\end{array}$ & Manguezal \\
\hline $\mathrm{P} 43$ & 4 & $\begin{array}{l}\text { Barra do rio Una em } \\
\text { Guarapari }\end{array}$ & $\begin{array}{l}20^{\circ} 37^{\prime} 52 ” \mathrm{~S} \\
40^{\circ} 26^{\prime} 41 " ’ \mathrm{~W}\end{array}$ & 0 & $1,5-2,0$ & $\mathrm{~T} 2$ & $\mathrm{Ae}$ & Praia arenosa & $\begin{array}{l}\text { Moderada } \\
\text { vegetação } \\
\text { emergente }\end{array}$ & $\begin{array}{l}\text { Restinga/ } \\
\text { habitação }\end{array}$ \\
\hline P44 & 5 & Lagoa Caraís/ Guarapari & $\begin{array}{l}20^{\circ} 36^{\prime} 43^{\prime \prime S} \\
40^{\circ} 25^{\prime} 04^{\prime \prime} \mathrm{W}\end{array}$ & 0 & 1,5 & $\mathrm{~T} 2$ & Ae- Ai-L & Mata de restinga & $\begin{array}{l}\text { Abundantes } \\
\text { macrófitas, taboas e } \\
\text { vegetação } \\
\text { emergente. }\end{array}$ & Restinga \\
\hline
\end{tabular}


Apêndice 3. Espécies de peixes conhecidas para as bacias do sudeste do Espírito Santo, pelo número de localidades amostradas e constância de ocorrência. Abreviaturas para os trechos: CRN- Cabeceiras do Rio Novo, BRN- Baixo Rio Novo, CRB- Cabeceira do Rio Benevente, BRB- Baixo Rio Benevente e MG- Microbacias de Guarapari. ${ }^{1}$ Espécies exóticas; ${ }^{2}$ Espécies estuarinas; ${ }^{3}$ espécies marinhas.

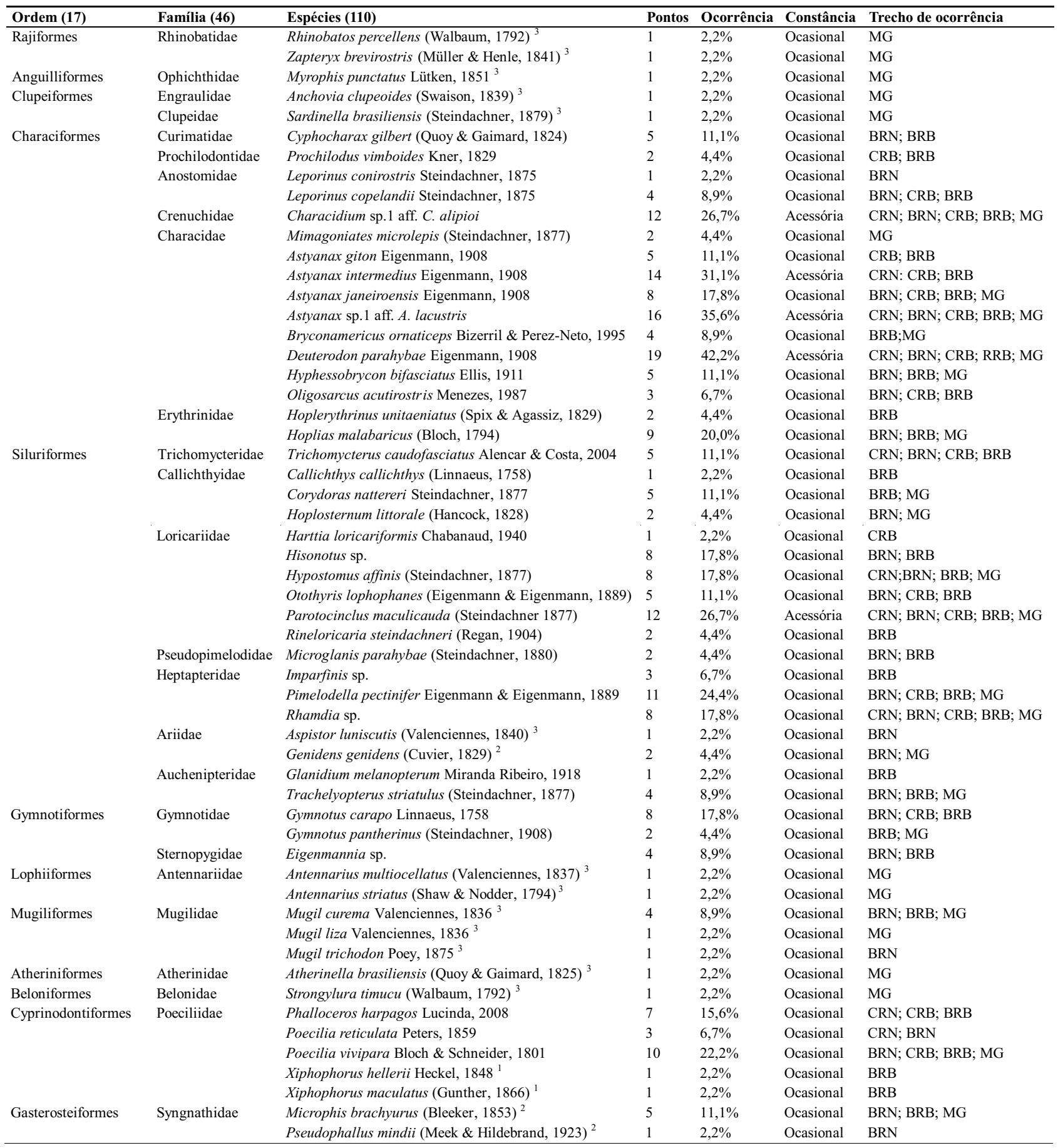




\begin{tabular}{|c|c|c|c|c|c|c|}
\hline Synbranchiformes & Synbranchidae & Synbranchus marmoratus Bloch, 1795 & 3 & $6,7 \%$ & Ocasional & BRN; CRN; BRB \\
\hline Scorpaeniformes & Triglidae & Prionotus punctatus (Bloch, 1793) ${ }^{3}$ & 1 & $2,2 \%$ & Ocasional & MG \\
\hline \multirow[t]{38}{*}{ Perciformes } & Centropomidae & Centropomus parallelus Poey, $1860^{2}$ & 2 & $4,4 \%$ & Ocasional & $\mathrm{BRN} ; \mathrm{MG}$ \\
\hline & & Centropomus undecimalis (Bloch, 1792) ${ }^{2}$ & 1 & $2,2 \%$ & Ocasional & BRN \\
\hline & Pomatomidae & Pomatomus saltatrix (Linnaeus, 1758) ${ }^{3}$ & 1 & $2,2 \%$ & Ocasional & MG \\
\hline & Carangidae & Caranx hippos (Linnaeus, 1766) ${ }^{3}$ & 1 & $2,2 \%$ & Ocasional & MG \\
\hline & & Caranx latus Agassiz, $1831^{3}$ & 3 & $6,7 \%$ & Ocasional & $\mathrm{BRN} ; \mathrm{MG}$ \\
\hline & & Chloroscombrus chrysurus (Linnaeus, 1766) ${ }^{3}$ & 1 & $2,2 \%$ & Ocasional & MG \\
\hline & Lutjanidae & Lutjanus jocu (Bloch \& Schneider, 1801) ${ }^{3}$ & 2 & $4,4 \%$ & Ocasional & $\mathrm{BRN} ; \mathrm{MG}$ \\
\hline & Gerreidae & Diapterus auratus Ranzani, $1840^{3}$ & 1 & $2,2 \%$ & Ocasional & MG \\
\hline & & Diapterus rhombeus (Cuvier, 1829) ${ }^{3}$ & 1 & $2,2 \%$ & Ocasional & $\mathrm{BRN}$ \\
\hline & & Eucinostomus melanopterus (Bleeker, 1863) ${ }^{3}$ & 2 & $4,4 \%$ & Ocasional & $\mathrm{BRN}$; MG \\
\hline & & Eugerres brasilianus (Cuvier, 1830) ${ }^{3}$ & 2 & $4,4 \%$ & Ocasional & BRN \\
\hline & & Ulaema lefroyi (Goode, 1874$)^{3}$ & 1 & $2,2 \%$ & Ocasional & MG \\
\hline & Haemulidae & Pomadasys crocro $(\text { Cuvier, } 1830)^{3}$ & 2 & $4,4 \%$ & Ocasional & MG \\
\hline & & Pomadasys ramosus (Poey, 1860$)^{3}$ & 2 & $4,4 \%$ & Ocasional & $\mathrm{BRB} ; \mathrm{MG}$ \\
\hline & & Paralonchurus brasiliensis (Steindachner, 1875) ${ }^{3}$ & 1 & $2,2 \%$ & Ocasional & MG \\
\hline & & Stellifer rastrifer (Jordan, 1889) ${ }^{3}$ & 1 & $2,2 \%$ & Ocasional & MG \\
\hline & Pomacanthidae & Holacanthus ciliaris (Linnaeus, 1758) ${ }^{3}$ & 1 & $2,2 \%$ & Ocasional & MG \\
\hline & Cichlidae & Australoheros muriae Ottoni \& Costa, 2008 & 5 & $11,1 \%$ & Ocasional & BRN; CRB \\
\hline & & Cichla pinima Kullander \& Ferreira, $2006^{1}$ & 3 & $6,7 \%$ & Ocasional & $\mathrm{BRN}$; BRB; MG \\
\hline & & Crenicichla lacustris (Castelnau, 1855) & 5 & $11,1 \%$ & Ocasional & CRN; BRN; BRB \\
\hline & & Geophagus brasiliensis (Quoy \& Gaimard, 1824) & 26 & $57,8 \%$ & Constante & CRN; BRN; CRB: BRB; MG \\
\hline & & Tilapia rendalli (Boulenger, 1897) $^{1}$ & 4 & $8,9 \%$ & Ocasional & $\mathrm{CRB} ; \mathrm{BRB} ; \mathrm{MG}$ \\
\hline & Scaridae & Selene vomer (Linnaeus, 1758$)^{3}$ & 1 & $2,2 \%$ & Ocasional & $\mathrm{BRB}$ \\
\hline & Blenniidae & Hypleurochilus fissicornis (Quoy \& Gaimard, 1824) ${ }^{3}$ & 1 & $2,2 \%$ & Ocasional & MG \\
\hline & & Scartella cristata (Linnaeus, 1758) ${ }^{3}$ & 1 & $2,2 \%$ & Ocasional & MG \\
\hline & Eleotridae & Dormitator maculatus (Bloch, 1792) ${ }^{2}$ & 2 & $4,4 \%$ & Ocasional & BRN \\
\hline & & Eleotris pisonis (Gmelin, 1789) ${ }^{2}$ & 3 & $6,7 \%$ & Ocasional & $\mathrm{BRN}$; MG \\
\hline & & Erotelis smaragdus (Valenciennes, 1837) ${ }^{3}$ & 1 & $2,2 \%$ & Ocasional & MG \\
\hline & & Guavina guavina (Valenciennes, 1837) ${ }^{3}$ & 1 & $2,2 \%$ & Ocasional & BRN \\
\hline & Gobiidae & Awaous tajasica Lichtenstein, 1822 & 6 & $13,3 \%$ & Ocasional & CRB; BRB \\
\hline & & Ctenogobius boleosoma (Jordan \& Gilbert, 1882) ${ }^{3}$ & 2 & $4,4 \%$ & Ocasional & $\mathrm{BRN} ; \mathrm{MG}$ \\
\hline & & Ctenogobius smaragdus (Valenciennes, 1837) ${ }^{3}$ & 1 & $2,2 \%$ & Ocasional & MG \\
\hline & & Ctenogobius stigmaticus (Poey, 1860) ${ }^{3}$ & 1 & $2,2 \%$ & Ocasional & MG \\
\hline & & Evorthodus lyricus (Girard, 1858) ${ }^{3}$ & 1 & $2,2 \%$ & Ocasional & BRN \\
\hline & & Gobionellus oceanicus (Pallas, 1770) ${ }^{3}$ & 2 & $4,4 \%$ & Ocasional & $\mathrm{BRN}$; MG \\
\hline & & Gobionellus stomatus Starks, $1913^{3}$ & 1 & $2,2 \%$ & Ocasional & MG \\
\hline & Sphyraenidae & Sphyraena guachancho Cuvier, $1829^{3}$ & 1 & $2,2 \%$ & Ocasional & MG \\
\hline & Stromateidae & Peprilus paru Linnaeus, $1758^{3}$ & 1 & $2,2 \%$ & Ocasional & MG \\
\hline \multirow[t]{4}{*}{ Pleuronectiformes } & Paralichthyidae & Citharichthys arenaceus Evermann \& Marsh, $1900^{2}$ & 2 & $4,4 \%$ & Ocasional & MG \\
\hline & & Citharichthys spilopterus Günther, $1862^{2}$ & 3 & $6,7 \%$ & Ocasional & $\mathrm{BRN}$; MG \\
\hline & & Paralichthys brasiliensis (Ranzani, 1842) $^{2}$ & 1 & $2,2 \%$ & Ocasional & MG \\
\hline & & Syacium papillosum (Linnaeus, 1758$)^{3}$ & 1 & $2,2 \%$ & Ocasional & MG \\
\hline \multirow[t]{6}{*}{ Tetraodontiformes } & Monacanthidae & Stephanolepis hispidus (Linnaeus, 1766) ${ }^{3}$ & 2 & $4,4 \%$ & Ocasional & MG \\
\hline & Tetraodontidae & Lagocephalus laevigatus (Linnaeus, 1766) ${ }^{3}$ & 1 & $2,2 \%$ & Ocasional & MG \\
\hline & & Sphoeroides greeleyi Gilbert, $1900^{3}$ & 1 & $2,2 \%$ & Ocasional & MG \\
\hline & & Sphoeroides spengleri (Bloch, 1785) ${ }^{3}$ & 1 & $2,2 \%$ & Ocasional & MG \\
\hline & & Sphoeroides testudineus (Linnaeus, 1758) ${ }^{3}$ & 2 & $4,4 \%$ & Ocasional & MG \\
\hline & Diodontidae & Cyclichthys spinosus (Linnaeus, 1758) ${ }^{3}$ & 1 & $2,2 \%$ & Ocasional & BRB \\
\hline
\end{tabular}


Apêndice 4. Relação da ocorrência das espécies (presença assinalada pela quantidade de exemplares coletados) na bacia do Rio Novo por ponto amostrado. (\%) ocorrência percentual na bacia.

\begin{tabular}{|c|c|c|c|c|c|c|c|c|c|c|c|c|c|c|c|c|}
\hline \multirow[b]{2}{*}{ Espécies/Pontos } & \multicolumn{5}{|c|}{ Cabeceiras } & \multicolumn{8}{|c|}{ Baixo } & \multirow[b]{2}{*}{ Total } & \multirow[b]{2}{*}{ Pontos } & \multirow[b]{2}{*}{$\%$} \\
\hline & P01 & $\mathrm{P} 02$ & $\mathrm{P} 03$ & P04 & P05 & P06 & P07 & P08 & P09 & $\mathrm{P} 10$ & P11 & $\mathrm{P} 12$ & $\mathrm{P} 13$ & & & \\
\hline Espécies dulcícolas (29) & 143 & 5 & 16 & 8 & 10 & 68 & 23 & 1 & 17 & 124 & 5 & 16 & 63 & 499 & 13 & \\
\hline Geophagus brasiliensis & 6 & 1 & 2 & 0 & 0 & 6 & 3 & 0 & 0 & 1 & 4 & 0 & 3 & 26 & 9 & $69,2 \%$ \\
\hline Astyanax sp. 1 aff. A. lacustris & 0 & 0 & 0 & 0 & 1 & 0 & 0 & 0 & 1 & 11 & 0 & 2 & 3 & 18 & 6 & $46,2 \%$ \\
\hline Deuterodon parahybae & 33 & 0 & 0 & 0 & 8 & 24 & 4 & 0 & 2 & 0 & 0 & 0 & 0 & 71 & 6 & $46,2 \%$ \\
\hline Astyanax intermedius & 101 & 4 & 4 & 2 & 0 & 0 & 0 & 0 & 0 & 0 & 0 & 0 & 0 & 111 & 5 & $38,5 \%$ \\
\hline Australoheros muriae & 0 & 0 & 0 & 0 & 0 & 2 & 0 & 0 & 0 & 17 & 0 & 6 & 10 & 35 & 5 & $38,5 \%$ \\
\hline Characidium sp.1 aff. C. alipioi & 0 & 0 & 8 & 2 & 0 & 0 & 0 & 1 & 0 & 0 & 0 & 0 & 0 & 11 & 4 & $30,8 \%$ \\
\hline Pimelodella pectinifer & 0 & 0 & 0 & 0 & 0 & 2 & 0 & 0 & 0 & 0 & 0 & 8 & 16 & 26 & 4 & $30,8 \%$ \\
\hline Poecilia vivipara & 0 & 0 & 0 & 0 & 0 & 0 & 0 & 0 & 14 & 11 & 0 & 0 & 22 & 47 & 4 & $30,8 \%$ \\
\hline Crenicichla lacustris & 0 & 0 & 0 & 1 & 0 & 9 & 0 & 0 & 0 & 0 & 0 & 0 & 0 & 10 & 3 & $23,1 \%$ \\
\hline Eigenmannia sp. & 0 & 0 & 0 & 0 & 0 & 6 & 0 & 0 & 0 & 4 & 0 & 0 & 0 & 10 & 3 & $23,1 \%$ \\
\hline Hisonotus sp. & 0 & 0 & 0 & 0 & 0 & 12 & 11 & 0 & 0 & 0 & 0 & 0 & 0 & 23 & 3 & $23,1 \%$ \\
\hline Hoplias malabaricus & 0 & 0 & 0 & 0 & 0 & 1 & 0 & 0 & 0 & 2 & 0 & 0 & 0 & 3 & 3 & $23,1 \%$ \\
\hline Hyphessobrycon bifascia tus & 0 & 0 & 0 & 0 & 0 & 0 & 0 & 0 & 0 & 45 & 0 & 0 & 1 & 46 & 3 & $23,1 \%$ \\
\hline Hypostomus affinis & 0 & 0 & 0 & 2 & 0 & 0 & 1 & 0 & 0 & 0 & 0 & 0 & 0 & 3 & 3 & $23,1 \%$ \\
\hline Parotocinclus maculicauda & 0 & 0 & 0 & 0 & 1 & 0 & 3 & 0 & 0 & 0 & 0 & 0 & 0 & 4 & 3 & $23,1 \%$ \\
\hline Rhamdia sp. & 0 & 0 & 0 & 1 & 0 & 0 & 0 & 0 & 0 & 1 & 0 & 0 & 0 & 2 & 3 & $23,1 \%$ \\
\hline Trichomycterus caudofasciatus & 0 & 0 & 2 & 0 & 0 & 0 & 1 & 0 & 0 & 0 & 0 & 0 & 0 & 3 & 3 & $23,1 \%$ \\
\hline Astyanax janeiroensis & 0 & 0 & 0 & 0 & 0 & 0 & 0 & 0 & 0 & 16 & 0 & 0 & 0 & 16 & 2 & $15,4 \%$ \\
\hline Cyphocharax gilbert & 0 & 0 & 0 & 0 & 0 & 0 & 0 & 0 & 0 & 5 & 0 & 0 & 0 & 5 & 2 & $15,4 \%$ \\
\hline Gymnotus carapo & 0 & 0 & 0 & 0 & 0 & 1 & 0 & 0 & 0 & 0 & 0 & 0 & 0 & 1 & 2 & $15,4 \%$ \\
\hline Hoplosternum littorale & 0 & 0 & 0 & 0 & 0 & 0 & 0 & 0 & 0 & 0 & 1 & 0 & 0 & 1 & 2 & $15,4 \%$ \\
\hline Lep orinus conirostris & 0 & 0 & 0 & 0 & 0 & 0 & 0 & 0 & 0 & 0 & 0 & 0 & 8 & 8 & 2 & $15,4 \%$ \\
\hline Leporinus copelandii & 0 & 0 & 0 & 0 & 0 & 1 & 0 & 0 & 0 & 0 & 0 & 0 & 0 & 1 & 2 & $15,4 \%$ \\
\hline Microglanis parahybae & 0 & 0 & 0 & 0 & 0 & 3 & 0 & 0 & 0 & 0 & 0 & 0 & 0 & 3 & 2 & $15,4 \%$ \\
\hline Oligosarcus acutirostris & 0 & 0 & 0 & 0 & 0 & 0 & 0 & 0 & 0 & 9 & 0 & 0 & 0 & 9 & 2 & $15,4 \%$ \\
\hline Otothyris lophophanes & 0 & 0 & 0 & 0 & 0 & 0 & 0 & 0 & 0 & 1 & 0 & 0 & 0 & 1 & 2 & $15,4 \%$ \\
\hline Phalloceros harpagos & 3 & 0 & 0 & 0 & 0 & 0 & 0 & 0 & 0 & 0 & 0 & 0 & 0 & 3 & 2 & $15,4 \%$ \\
\hline Synbranchus marmoratus & 0 & 0 & 0 & 0 & 0 & 1 & 0 & 0 & 0 & 0 & 0 & 0 & 0 & 1 & 2 & $15,4 \%$ \\
\hline Trachelyopterus striatulus & 0 & 0 & 0 & 0 & 0 & 0 & 0 & 0 & 0 & 1 & 0 & 0 & 0 & 1 & 2 & $15,4 \%$ \\
\hline Espécies introduzidas (2) & $\mathbf{0}$ & 7 & 3 & 0 & 0 & $\mathbf{0}$ & 11 & $\mathbf{0}$ & $\mathbf{0}$ & 2 & $\mathbf{0}$ & $\mathbf{0}$ & $\mathbf{0}$ & 23 & 5 & \\
\hline Poecilia reticulata & 0 & 7 & 3 & 0 & 0 & 0 & 11 & 0 & 0 & 0 & 0 & 0 & 0 & 21 & 4 & $30,8 \%$ \\
\hline Cichla pinima & 0 & 0 & 0 & 0 & 0 & 0 & 0 & 0 & 0 & 2 & 0 & 0 & 0 & 2 & 2 & $15,4 \%$ \\
\hline Espécies estuarinas (7) & $\mathbf{0}$ & $\mathbf{0}$ & $\mathbf{0}$ & $\mathbf{0}$ & $\mathbf{0}$ & 3 & $\mathbf{0}$ & $\mathbf{0}$ & $\mathbf{0}$ & $\mathbf{0}$ & 1 & 46 & 51 & 101 & 5 & \\
\hline Microphis brachyurus & 0 & 0 & 0 & 0 & 0 & 3 & 0 & 0 & 0 & 0 & 0 & 30 & 27 & 60 & 4 & $30,8 \%$ \\
\hline Dormitator maculatus & 0 & 0 & 0 & 0 & 0 & 0 & 0 & 0 & 0 & 0 & 0 & 3 & 10 & 13 & 3 & $23,1 \%$ \\
\hline Eleotris pisonis & 0 & 0 & 0 & 0 & 0 & 0 & 0 & 0 & 0 & 0 & 0 & 7 & 9 & 16 & 3 & $23,1 \%$ \\
\hline Centropomus parallelus & 0 & 0 & 0 & 0 & 0 & 0 & 0 & 0 & 0 & 0 & 1 & 0 & 0 & 1 & 2 & $15,4 \%$ \\
\hline Centropomus undecimalis & 0 & 0 & 0 & 0 & 0 & 0 & 0 & 0 & 0 & 0 & 0 & 0 & 4 & 4 & 2 & $15,4 \%$ \\
\hline Citharichthys spilopt erus & 0 & 0 & 0 & 0 & 0 & 0 & 0 & 0 & 0 & 0 & 0 & 6 & 0 & 6 & 2 & $15,4 \%$ \\
\hline Pseudophallus mindii & 0 & 0 & 0 & 0 & 0 & 0 & 0 & 0 & 0 & 0 & 0 & 0 & 1 & 1 & 2 & $15,4 \%$ \\
\hline Espécies marinhas (14) & $\mathbf{0}$ & $\mathbf{0}$ & $\mathbf{0}$ & 0 & 0 & $\mathbf{0}$ & $\mathbf{0}$ & $\mathbf{0}$ & $\mathbf{0}$ & $\mathbf{0}$ & 9 & 88 & 35 & 132 & 4 & \\
\hline Caranx latus & 0 & 0 & 0 & 0 & 0 & 0 & 0 & 0 & 0 & 0 & 8 & 23 & 0 & 31 & 3 & $23,1 \%$ \\
\hline Eugerres brasilianus & 0 & 0 & 0 & 0 & 0 & 0 & 0 & 0 & 0 & 0 & 1 & 1 & 0 & 2 & 3 & $23,1 \%$ \\
\hline Bathygobius soporator & 0 & 0 & 0 & 0 & 0 & 0 & 0 & 0 & 0 & 0 & 0 & 2 & 0 & 2 & 2 & $15,4 \%$ \\
\hline Ctenogobius boleosoma & 0 & 0 & 0 & 0 & 0 & 0 & 0 & 0 & 0 & 0 & 0 & 0 & 12 & 12 & 2 & $15,4 \%$ \\
\hline Diapterus rhombeus & 0 & 0 & 0 & 0 & 0 & 0 & 0 & 0 & 0 & 0 & 0 & 2 & 0 & 2 & 2 & $15,4 \%$ \\
\hline Eucinostomus melanopterus & 0 & 0 & 0 & 0 & 0 & 0 & 0 & 0 & 0 & 0 & 0 & 22 & 0 & 22 & 2 & $15,4 \%$ \\
\hline Evorthodus lyricus & 0 & 0 & 0 & 0 & 0 & 0 & 0 & 0 & 0 & 0 & 0 & 0 & 7 & 7 & 2 & $15,4 \%$ \\
\hline Genidens genidens & 0 & 0 & 0 & 0 & 0 & 0 & 0 & 0 & 0 & 0 & 0 & 29 & 0 & 29 & 2 & $15,4 \%$ \\
\hline Gobionellus oceanicus & 0 & 0 & 0 & 0 & 0 & 0 & 0 & 0 & 0 & 0 & 0 & 0 & 15 & 15 & 2 & $15,4 \%$ \\
\hline Guavina guavina & 0 & 0 & 0 & 0 & 0 & 0 & 0 & 0 & 0 & 0 & 0 & 1 & 0 & 1 & 2 & $15,4 \%$ \\
\hline Lutjanus jocu & 0 & 0 & 0 & 0 & 0 & 0 & 0 & 0 & 0 & 0 & 0 & 2 & 0 & 2 & 2 & $15,4 \%$ \\
\hline Mugil curema & 0 & 0 & 0 & 0 & 0 & 0 & 0 & 0 & 0 & 0 & 0 & 0 & 1 & 1 & 2 & $15,4 \%$ \\
\hline Mugil trichodon & 0 & 0 & 0 & 0 & 0 & 0 & 0 & 0 & 0 & 0 & 0 & 6 & 0 & 6 & 2 & $15,4 \%$ \\
\hline
\end{tabular}


Apêndice 5. Relação da ocorrência das espécies (presença assinalada pela quantidade de exemplares coletados) na bacia do rio Benevente por ponto amostrado. (\%) ocorrência percentual na bacia.

\begin{tabular}{|c|c|c|c|c|c|c|c|c|c|c|c|c|c|c|c|c|c|c|c|c|c|c|c|c|}
\hline & \multicolumn{7}{|c|}{ Cabeceiras } & \multicolumn{14}{|c|}{ Baixo } & \multirow[b]{2}{*}{ Total } & \multirow[b]{2}{*}{ Pontos } & \multirow[b]{2}{*}{$\%$} \\
\hline Espécies/Pontos & P14 & P15 & P16 & P17 & P18 & P19 & P20 & P21 & P22 & P23 & P24 & $\mathrm{P} 25$ & P26 & P27 & P28 & P29 & $\mathrm{P} 30$ & P31 & $\mathrm{P} 32$ & P33 & P34 & & & \\
\hline Espécies dulcícolas (39) & 16 & 33 & 33 & 61 & 22 & 35 & 89 & 7 & 51 & 25 & 62 & 669 & 143 & 2 & 11 & 5 & 721 & 1514 & 21 & 23 & 94 & 3.637 & 21 & \\
\hline Geophagus brasiliensis & 0 & 11 & 1 & 3 & 2 & 5 & 9 & 1 & 3 & 0 & 1 & 6 & 0 & 0 & 3 & 0 & 51 & 24 & 1 & 0 & 6 & 127 & 15 & $71,4 \%$ \\
\hline Deuterodon parahybae & 0 & 4 & 0 & 11 & 3 & 7 & 13 & 0 & 1 & 0 & 0 & 146 & 5 & 0 & 0 & 0 & 107 & 64 & 0 & 12 & 0 & 373 & 11 & $52,4 \%$ \\
\hline Astyanax intermedius & 1 & 0 & 1 & 0 & 4 & 0 & 7 & 0 & 17 & 1 & 5 & 11 & 17 & 0 & 0 & 0 & 0 & 172 & 0 & 0 & 0 & 236 & 10 & $47,6 \%$ \\
\hline Astyanax sp. 1 aff. A. lacustris & 0 & 0 & 0 & 0 & 0 & 0 & 1 & 1 & 5 & 0 & 0 & 16 & 0 & 1 & 0 & 0 & 3 & 9 & 2 & 5 & 2 & 45 & 10 & $47,6 \%$ \\
\hline Parotocinclus maculicauda & 0 & 7 & 0 & 0 & 0 & 0 & 0 & 0 & 14 & 5 & 1 & 8 & 33 & 0 & 0 & 0 & 24 & 25 & 0 & 0 & 0 & 117 & 8 & $38,1 \%$ \\
\hline Characidium sp. 1 aff. C. alipioi & 0 & 0 & 3 & 0 & 0 & 0 & 0 & 0 & 1 & 0 & 0 & 68 & 22 & 0 & 2 & 0 & 9 & 3 & 0 & 0 & 0 & 108 & 7 & $33,3 \%$ \\
\hline Pimelodella pectinifer & 0 & 0 & 0 & 0 & 0 & 0 & 4 & 0 & 2 & 3 & 0 & 13 & 13 & 0 & 0 & 0 & 10 & 5 & 0 & 0 & 0 & 50 & 7 & $33,3 \%$ \\
\hline Awaous tajasica & 0 & 0 & 0 & 0 & 0 & 0 & 2 & 0 & 0 & 1 & 1 & 0 & 0 & 1 & 0 & 3 & 0 & 1 & 0 & 0 & 0 & 9 & 6 & $28,6 \%$ \\
\hline Hisonotus sp. & 0 & 0 & 0 & 0 & 0 & 0 & 0 & 0 & 1 & 0 & 35 & 38 & 11 & 0 & 0 & 0 & 115 & 278 & 0 & 0 & 0 & 478 & 6 & $28,6 \%$ \\
\hline Hoplias malabaricus & 0 & 0 & 0 & 0 & 0 & 0 & 0 & 0 & 1 & 2 & 0 & 3 & 0 & 0 & 0 & 0 & 2 & 11 & 0 & 0 & 4 & 23 & 6 & $28,6 \%$ \\
\hline Phalloceros harpagos & 0 & 0 & 0 & 41 & 4 & 23 & 8 & 0 & 1 & 0 & 0 & 0 & 0 & 0 & 1 & 0 & 0 & 0 & 0 & 0 & 0 & 78 & 6 & $28,6 \%$ \\
\hline Astyanax giton & 0 & 4 & 0 & 0 & 0 & 0 & 15 & 1 & 2 & 0 & 0 & 0 & 0 & 0 & 0 & 0 & 0 & 0 & 0 & 5 & 0 & 27 & 5 & $23,8 \%$ \\
\hline Astyanax janeiroensis & 0 & 0 & 0 & 6 & 0 & 0 & 0 & 0 & 0 & 0 & 0 & 31 & 0 & 0 & 1 & 0 & 284 & 630 & 0 & 0 & 0 & 952 & 5 & $23,8 \%$ \\
\hline Hypostomus affinis & 0 & 0 & 0 & 0 & 0 & 0 & 0 & 1 & 0 & 0 & 0 & 2 & 2 & 0 & 0 & 0 & 31 & 9 & 0 & 0 & 0 & 45 & 5 & $23,8 \%$ \\
\hline Cyphocharax gilbert & 0 & 0 & 0 & 0 & 0 & 0 & 0 & 1 & 0 & 0 & 0 & 1 & 0 & 0 & 0 & 0 & 1 & 4 & 0 & 0 & 0 & 7 & 4 & $19,0 \%$ \\
\hline Otothyris lophophanes & 0 & 1 & 0 & 0 & 0 & 0 & 0 & 0 & 0 & 0 & 3 & 0 & 17 & 0 & 0 & 0 & 0 & 1 & 0 & 0 & 0 & 22 & 4 & $19,0 \%$ \\
\hline Poecilia vivipara & 0 & 1 & 0 & 0 & 0 & 0 & 0 & 0 & 1 & 0 & 0 & 1 & 0 & 0 & 0 & 0 & 0 & 0 & 18 & 0 & 0 & 21 & 4 & $19,0 \%$ \\
\hline Crenicichla lacustris & 0 & 0 & 0 & 0 & 0 & 0 & 0 & 0 & 0 & 4 & 0 & 0 & 9 & 0 & 0 & 0 & 6 & 0 & 0 & 0 & 0 & 19 & 3 & $14,3 \%$ \\
\hline Imparfinis sp. & 0 & 0 & 0 & 0 & 0 & 0 & 0 & 2 & 0 & 0 & 0 & 23 & 0 & 0 & 0 & 0 & 3 & 0 & 0 & 0 & 0 & 28 & 3 & $14,3 \%$ \\
\hline Leporinus copelandii & 0 & 0 & 0 & 0 & 0 & 0 & 1 & 0 & 0 & 1 & 4 & 0 & 0 & 0 & 0 & 0 & 0 & 0 & 0 & 0 & 0 & 6 & 3 & $14,3 \%$ \\
\hline Trichomycterus caudofasciatus & 0 & 0 & 0 & 0 & 0 & 0 & 1 & 0 & 0 & 0 & 0 & 3 & 1 & 0 & 0 & 0 & 0 & 0 & 0 & 0 & 0 & 5 & 3 & $14,3 \%$ \\
\hline Bryconamericus ornaticeps & 0 & 0 & 0 & 0 & 0 & 0 & 0 & 0 & 0 & 0 & 0 & 0 & 13 & 0 & 0 & 0 & 0 & 63 & 0 & 0 & 0 & 76 & 2 & $9,5 \%$ \\
\hline Eigenmannia sp. & 0 & 0 & 0 & 0 & 0 & 0 & 0 & 0 & 0 & 0 & 0 & 0 & 0 & 0 & 0 & 0 & 3 & 1 & 0 & 0 & 0 & 4 & 2 & $9,5 \%$ \\
\hline Hoplerythrinus unitaeniatus & 0 & 0 & 0 & 0 & 0 & 0 & 0 & 0 & 0 & 0 & 0 & 0 & 0 & 0 & 0 & 2 & 2 & 0 & 0 & 0 & 0 & 4 & 2 & $9,5 \%$ \\
\hline Hyphessobrycon bifasciatus & 0 & 0 & 0 & 0 & 0 & 0 & 0 & 0 & 0 & 0 & 0 & 6 & 0 & 0 & 0 & 0 & 0 & 0 & 0 & 0 & 82 & 88 & 2 & $9,5 \%$ \\
\hline Oligosarcus acutirostris & 0 & 0 & 0 & 0 & 0 & 0 & 12 & 0 & 0 & 0 & 0 & 1 & 0 & 0 & 0 & 0 & 0 & 0 & 0 & 0 & 0 & 13 & 2 & $9,5 \%$ \\
\hline Rineloricaria steindachneri & 0 & 0 & 0 & 0 & 0 & 0 & 0 & 0 & 0 & 1 & 0 & 0 & 0 & 0 & 0 & 0 & 1 & 0 & 0 & 0 & 0 & 2 & 2 & $9,5 \%$ \\
\hline Synbranchus marmoratus & 15 & 0 & 0 & 0 & 0 & 0 & 0 & 0 & 0 & 0 & 0 & 0 & 0 & 0 & 0 & 0 & 2 & 0 & 0 & 0 & 0 & 17 & 2 & $9,5 \%$ \\
\hline Trachelyopterus striatulus & 0 & 0 & 0 & 0 & 0 & 0 & 0 & 0 & 0 & 0 & 0 & 0 & 0 & 0 & 0 & 0 & 1 & 6 & 0 & 0 & 0 & 7 & 2 & $9,5 \%$ \\
\hline Australoheros muriae & 0 & 1 & 0 & 0 & 0 & 0 & 0 & 0 & 0 & 0 & 0 & 0 & 0 & 0 & 0 & 0 & 0 & 0 & 0 & 0 & 0 & 1 & 1 & $4,8 \%$ \\
\hline Callichthys callichthys & 0 & 0 & 0 & 0 & 0 & 0 & 0 & 0 & 0 & 0 & 0 & 0 & 0 & 0 & 4 & 0 & 0 & 0 & 0 & 0 & 0 & 4 & 1 & $4,8 \%$ \\
\hline Harttia loricariformis & 0 & 0 & 0 & 0 & 0 & 0 & 7 & 0 & 0 & 0 & 0 & 0 & 0 & 0 & 0 & 0 & 0 & 0 & 0 & 0 & 0 & 7 & 1 & $4,8 \%$ \\
\hline Microglanis parahybae & 0 & 0 & 0 & 0 & 0 & 0 & 0 & 0 & 0 & 0 & 6 & 0 & 0 & 0 & 0 & 0 & 0 & 0 & 0 & 0 & 0 & 6 & 1 & $4,8 \%$ \\
\hline Prochilodus vimboides & 0 & 0 & 0 & 0 & 0 & 0 & 2 & 0 & 0 & 0 & 0 & 0 & 0 & 0 & 0 & 0 & 0 & 0 & 0 & 0 & 0 & 2 & 1 & $4,8 \%$ \\
\hline Espécies introduzidas (4) & $\mathbf{0}$ & $\mathbf{0}$ & 19 & $\mathbf{0}$ & 34 & $\mathbf{0}$ & $\mathbf{0}$ & 28 & 1 & $\mathbf{0}$ & $\mathbf{0}$ & $\mathbf{0}$ & $\mathbf{0}$ & $\mathbf{0}$ & $\mathbf{0}$ & $\mathbf{0}$ & $\mathbf{0}$ & $\mathbf{0}$ & 4 & $\mathbf{0}$ & 1 & 87 & 6 & \\
\hline Tilapia rendalli & 0 & 0 & 19 & 0 & 34 & 0 & 0 & 0 & 0 & 0 & 0 & 0 & 0 & 0 & 0 & 0 & 0 & 0 & 4 & 0 & 0 & 57 & 3 & $14,3 \%$ \\
\hline Cichla pinima & 0 & 0 & 0 & 0 & 0 & 0 & 0 & 0 & 0 & 0 & 0 & 0 & 0 & 0 & 0 & 0 & 0 & 0 & 0 & 0 & 1 & 1 & 1 & $4,8 \%$ \\
\hline Xiphophorus helleri & 0 & 0 & 0 & 0 & 0 & 0 & 0 & 28 & 0 & 0 & 0 & 0 & 0 & 0 & 0 & 0 & 0 & 0 & 0 & 0 & 0 & 28 & 1 & $4,8 \%$ \\
\hline Xiphophorus maculatus & 0 & 0 & 0 & 0 & 0 & 0 & 0 & 0 & 1 & 0 & 0 & 0 & 0 & 0 & 0 & 0 & 0 & 0 & 0 & 0 & 0 & 1 & 1 & $4,8 \%$ \\
\hline Espécies estuarinas (1) & $\mathbf{0}$ & 0 & O & 0 & 0 & 0 & 0 & 0 & 0 & 0 & 0 & 0 & 0 & 0 & 0 & 0 & 1 & 0 & 0 & 0 & 0 & 1 & 1 & $4,8 \%$ \\
\hline Microphis brachyurus & 0 & 0 & 0 & 0 & 0 & 0 & 0 & 0 & 0 & 0 & 0 & 0 & 0 & 0 & 0 & 0 & 1 & 0 & 0 & 0 & 0 & 1 & 1 & $4,8 \%$ \\
\hline Espécies marinhas (14) & $\mathbf{0}$ & $\mathbf{0}$ & $\mathbf{0}$ & $\mathbf{0}$ & $\mathbf{0}$ & $\mathbf{0}$ & 0 & $\mathbf{0}$ & $\mathbf{0}$ & $\mathbf{0}$ & $\mathbf{0}$ & $\mathbf{0}$ & $\mathbf{0}$ & $\mathbf{0}$ & 0 & 2 & 0 & $\mathbf{0}$ & 0 & 0 & $\mathbf{0}$ & 2 & 1 & $4,8 \%$ \\
\hline Ciclichthys spinosus & 0 & 0 & 0 & 0 & 0 & 0 & 0 & 0 & 0 & 0 & 0 & 0 & 0 & 0 & 0 & 1 & 0 & 0 & 0 & 0 & 0 & 1 & 1 & $4,8 \%$ \\
\hline Mugil curema & 0 & 0 & 0 & 0 & 0 & 0 & 0 & 0 & 0 & 0 & 0 & 0 & 0 & 0 & 0 & 1 & 0 & 0 & 0 & 0 & 0 & 1 & 1 & $4,8 \%$ \\
\hline
\end{tabular}


Apêndice 6. Relação da ocorrência das espécies (presença assinalada pela quantidade de exemplares coletados) nas microbacias de Guarapari por ponto amostrado. (\%) ocorrência percentual na bacia.

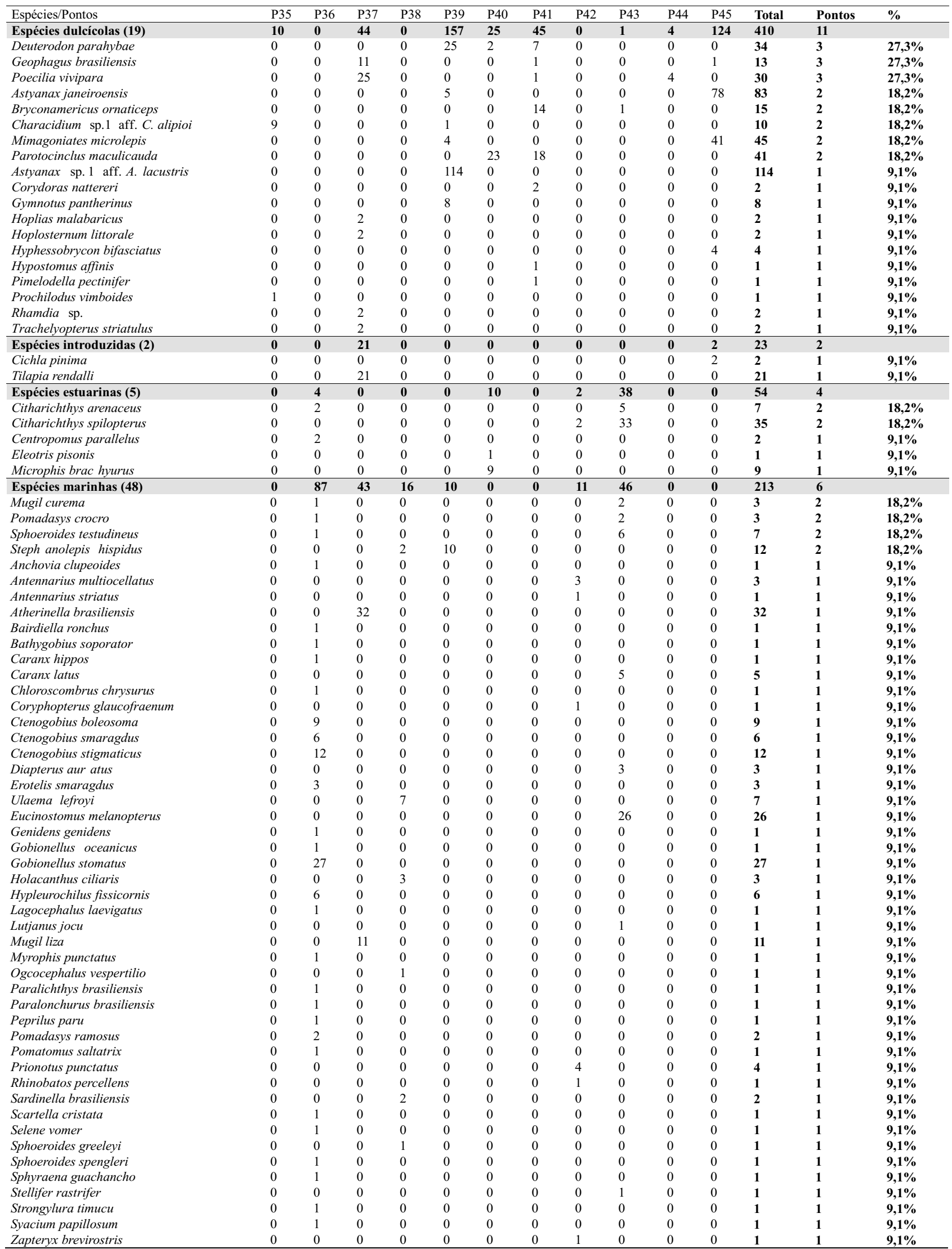

